\title{
The effect of particle polydispersion in a gasifier bed dynamics using Eulerian-Eulerian models
}

\author{
Ana Cubero ${ }^{\mathrm{a}, \mathrm{b}}$, Alberto Sánchez-Insa ${ }^{\mathrm{a}, \mathrm{b}}$, Norberto Fueyo ${ }^{\mathrm{a}, \mathrm{b}, *}$ \\ ${ }^{a}$ Fluid Dynamics Group, University of Zaragoza, María de Luna 3, 50018 Zaragoza, Spain \\ ${ }^{b}$ LIFTEC/CSIC, María de Luna 10, 50018 Zaragoza, Spain
}

\begin{abstract}
The influence of the coal particle size distribution on the performance of a fluidized bed gasifier is investigated by means of a multiphase Eulerian-Eulerian model embodied in the OpenFOAM CFD code. To distinguish the effects of combustion from those of particle segregation we compare the solutions obtained by modeling of solids as, alternatively, monodispersed or polydispersed particles; and as reactive or inert ones. Results reveal that the preferential motion of the smaller particles towards the bed top significantly delays char consumption at the bottom layers, favors volatile oxidation, and results in a more uneven lateral distribution of the off-gas.
\end{abstract}

Keywords: Fluidized bed, fuel particle size distribution, gasification, Eulerian-Eulerian model, OpenFOAM

\footnotetext{
${ }^{*}$ Corresponding author. Tel.: +34 976762153; fax: +34 976761882.

Email addresses: anac@unizar.es (Ana Cubero), albertos@unizar.es (Alberto Sánchez-Insa), norberto.fueyo@unizar.es (Norberto Fueyo)
} 


\section{Nomenclature}

$C_{p} \quad$ Heat capacity

$T \quad$ Temperature

$f_{q p}^{h} \quad$ Interphase heat-transfer coefficient for heat conduction between phases $p$ and $q$

$f_{q p}^{\vec{v}} \quad$ Drag-force coefficient from phase $q$ to phase $p$

$\vec{g} \quad$ Gravitational acceleration

$g, s \quad$ Gas and solid phase

$\dot{m}_{q p}^{x, \alpha} \quad$ Mass transfer rate of species $\alpha$ from phase $q$ into phase $p$ due to process $x$

$p, q \quad$ Generic phases

$r \quad$ Phase volume fraction

$\vec{v} \quad$ Velocity vector

$x \quad$ Mass-exchanging process $\quad \rho \quad$ Density

$y_{p}^{\alpha} \quad$ Mass fraction of species $\alpha$ in phase $p \quad \overrightarrow{\vec{\tau}}_{p} \quad$ Stress tensor $\dot{\omega}_{p}^{r, \alpha}$ Chemical reaction rate for species $\alpha$ due to homogeneous reaction $r$ in phase $p$

$\alpha \quad$ Chemical species

$\Delta h_{f_{p}}^{\alpha}$ Specific formation enthalpy of species $\alpha$ in phase $p$

$\Gamma_{p}^{\alpha} \quad$ Diffusion coefficient for species $\alpha$ in phase $p$

$\kappa_{p} \quad$ Thermal conductivity of phase $p$

$\phi_{x} \quad$ Value of a (generic) variable $\phi$ in the donor phase in mass-exchanging process $x$

\section{Introduction}

Fluidized bed technology is often used for the combustion of solid fuels because it provides intense mixing and good temperature control. However, there is still a lack of fundamental knowledge about the complex phenomena present in these multiphase, reactive systems. Intense gas-particle and particle-particle interactions, with phase mixing, segregation and separation, develop as the intervening particles heat up, the volatile matter is released, and heterogeneous gas-solid reactions and homogeneous reactions among the gas species take place.

Particles in fluidized beds are usually not monodisperse; and the relevance of polydispersion on the hydrodynamics of fluidization is often recognized in the literature. The majority of experimental and computational studies that investigate the effects of particle segregation 
consider binary mixtures with two particle types that differ in size or density. Examples of different computational approaches are reported by Mathiesen et al. [40], van Wachem et al. [66], van Sint Annaland et al. [65] or Gera et al. [23]; experimental investigations are reviewed by Joseph et al. [34] or Zhang et al. [78].

However, fuel particles in industrial applications do not have generally a single size, and relatively few investigations include continuous particle size distributions. Size-dependent particle-behavior has been reported in the literature; for instance, the preference of larger particles towards the bottom layers in the bed and of smaller ones towards the top layers; or the effect of the size range on the extent of segregation (see, for example, $[6,21,37]$ ). The computational work of Dahl and Hrenya using Gaussian and lognormal distributions for inert beds concluded that the shape of the size distribution in the central layers of a bubbling fluidized bed is similar to the initial, overall one [18].

This behavior was later ratified by the experimental measurements reported by Chew et al. [12]. This same research group carried out a series of experiments to study the impact of the size-distribution width on axial and radial segregation, elutriation or bubble patterns $[9,10,11]$.

These studies investigated the influence of polydispersion on the flow pattern for an inert bed. When the bed is a reacting one, fuel particle segregation affects not only the hydrodynamics of fluidization but also interphase-transfer phenomena and reaction rates. The relevance of fines on the performance of fluidized bed reactors has been long recognized by the operators of industrial processes, and their addition is a common practice during long periods of operation. Grace and Sun ([28], [60]) studied experimentally the effect of the particle size distribution (PSD) on the conversion and reactor efficiency in fluidized beds by evaluating the gas-solid contact efficiency. They used the method known as hot-model reaction, that employs a simple reaction (typically the first order, catalytic ozone decomposition) in order to measure the reactant conversion under controlled conditions [67]. In this method, however, the reciprocal influence of chemical conversion on flow hydrodynamics cannot be ascertained. For example, the volatile plume in the vicinity of the solid fuel feed may result in the maldistribution of solid-gas mixtures [27].

The fundamental understanding of the hydrodynamics of fluidization and its coupling with fuel combustion will allow the improvement of design strategies. It has been shown that it 
is difficult to understand and control the conversion processes in fluidized beds using solely empirical approaches. In this context, Computational Fluid Dynamics (CFD) models provides essential information to better understand the complex physical and chemical processes involved; CFD models are even expected by some authors to replace, in the future, empirical or semi-empirical models in the design of large scale units [54].

Review articles on CFD approaches to combustion and gasification in fluidized beds have been published recently [49, 54, 79]; they compare and highlight the challenges and needs of the two main strategies for solving the evolution of solids in the bed: the Eulerian and Lagrangian formulations.

Eulerian-Eulerian models treat all the phases (gas and solid) as inter-penetrating continua, each phase being governed by a set of Navier-Stokes equations. This approach requires an important modeling effort in order to evaluate the solid-phase constitutive relationships (often by applying the Kinetic Theory of Granular Flows (KTGF) in configurations with large particle-number densities), and the interphase interactions (often based on semi-empirical correlations) [25]. Multiple sizes can be accommodated extending the KTGF approach [41] or using quadrature-based moment methods [45, 53].

Eulerian-Lagrangian models consider the solid phases as discrete particles and the motion of each individual particle is described by a Lagrangian equation embodying Newton's second law. The originate from the Particle-in-Cell method arising out of Los Alamos National Laboratory in the USA for handling numerically flow discontinuities [30]. The basic algorithm for solving the flow of coupled continuum-disperse phases using Eulerian-Lagrangian models was first proposed by Crowe et al. [14] as the Particle-Source-In Cell (or PSI-CELL) algorithm.

As originally formulated, the Lagrangian approach to multiphase modeling was not applicable to dense flows, and did not accommodate particle-particle interactions that are paramount in fluidized beds. The so-called Multiphase Particle-In-Cell alternative, or MP-PIC [4, 55, 57], uses a dual Lagrangian-Eulerian framework for the disperse phase, whereby the particle information is transferred to the Eulerian mesh to calculate the particle stresses due to particleparticle interaction; the stresses are then transferred back to the Lagrangian formulation.

An alternative Lagrangian approach to the modeling of dense flows arose out of the Discrete Element Method, or DEM, developed for the simulation of granular flows [17]. Particle-particle interaction is treated by including a contact model, and the inter-particle forces resulting from 
it. The extension of DEM to include a continuous, fluid phase is known as CFD-DEM, and has been used for the simulation of fluidized beds [59, 64].

Zhong et al. [79] conclude that both Eulerian and Lagrangian approaches are promising for the solution of dense particulate reaction systems, although some difficulties still need to be overcome: the change of particle size and shape, the coupling of the flow with chemical reactions, and the computational requirements.

In the present work we use an Eulerian-Eulerian model to analyze the effect of the size distribution of coal particles in a fluidized bed gasifier. The solids are a mixture of limestone and coal; coal is continuously fed through a single lateral port.

A number of authors have applied Eulerian-Eulerian models to coal or biomass gasification $[5,24,69,76]$. However, their approaches present some limitations in the modeling of the solid phases, such as the use of the same phase for describing both coal and limestone particles, or the assumption of constant density and diameter for the reacting phase.

More comprehensive algorithms which account for devolatilization and chemical reactions of fuel particles in a bed that includes an inert phase are reported in [33, 52, 72, 74, 82]. Fuel particles, however, are represented as having a single diameter. Some authors have modeled a fluidized bed using a size distribution of particles that undergo devolatilization by an inert gas, but without including heterogeneous or homogeneous reactions [38, 73, 75].

Recently, using a multi-fluid algorithm coupled with chemical reactions, Chen et al. [8] have modeled the gasification of biomass and coal, and Zeneli et al. [77] have simulated the sorbent calcination/carbonation in a coal reactor. In both cases two solid phases are used for representing two types of reactive particles (with different diameter, density, composition).

As for Eulerian-Lagrangian approaches, there are a few recent articles reporting the comprehensive simulation of continuous particle size distributions and combustion and gasification reactions (as, for example, the CFD-DEM method presented by $\mathrm{Ku}$ et al. [36] or the MP-PIC models applied by Snider et al. [56] or Xie et al. [71]). However, a comparison of the reactor performance with the monodisperse case is not provided, preventing therefore the analysis of the effect of the distribution width.

The multi-fluid Eulerian-Eulerian algorithm presented in this work has been developed and implemented by the authors in the open-source platform OpenFOAM $[2,70]$. It allows the simultaneous study of fuel polydispersion and chemical reactions in a fluidized bed. Our 
model is based on the Kinetic Theory of Granular Flows, and can handle an arbitrary number of solid phases by using multiple granular temperatures [40]. Each solid phase can have multiple components (such as moisture, ash, char), and its density is allowed to change as the particles undergo drying, devolatilization and heterogeneous reactions.

The main goal of the present study is to provide some insight into the coupling between hydrodynamics and gasification kinetics when fuel particles are segregated by sizes in the

fluidized bed. To do so, we compare solutions obtained with coal particles represented by a single size and by a realistic particle size distribution. Additionally, the same bed with the same operating conditions is solved as an inert one, so that we are able to compare the hydrodynamic behavior of the reactive bed with that of the inert one.

The remainder article is structured as follows. First, we present our formulation for the multiphase flow with mass transfer and chemical reaction. Then we describe the solution algorithm, the fluidized bed gasifier used in the simulations, and our main results. We analyze first the effect of the particle size distribution on the hydrodynamic patterns in both inert and reactive beds, and then its influence on the spatial distribution of reaction rates and species. We end with some concluding remarks.

\section{Eulerian-Eulerian conservation equations with mass transfer and chemical re- action}

We postulate a general formulation for the Eulerian-Eulerian conservation equations governing the multispecies and multiphase gas-solid flows with mass transfer and chemical reaction.

The balance equation for the mass fraction of a gas species $y\left(\right.$ such $\mathrm{O}_{2}$ or $\mathrm{CO}_{2}$ ) or a particle component (such as moisture or ash) $\alpha$ in phase $p\left(y_{p}^{\alpha}\right)$ is written as:

$$
\frac{\partial\left(r_{p} \rho_{p} y_{p}^{\alpha}\right)}{\partial t}+\nabla \cdot\left(r_{p} \rho_{p} \vec{v}_{p} y_{p}^{\alpha}\right)+\nabla \cdot\left(r_{p} \Gamma_{p}^{\alpha} \nabla y_{p}^{\alpha}\right)=\sum_{x} \sum_{q} \dot{m}_{q p}^{x, \alpha}+\sum_{r} \dot{\omega}_{p}^{r, \alpha}
$$

$\dot{m}_{q p}^{x, \alpha}$ is the mass transfer rate of species $\alpha$ from phase $q$ into phase $p$ due to the process $x$ (for example, devolatilization). This term also accounts for heterogeneous reactions; in this case, $\dot{m}_{p p}^{x, \alpha}$ is the rate of consumption or production of species $\alpha$ in phase $p . \dot{\omega}_{p}^{r, \alpha}$ is the generation of species $\alpha$ in phase $p$ due to the homogeneous chemical reaction $r$ (for example, the reaction 
rate of $\mathrm{H}_{2}$ in the water-gas shift reaction). $r_{p}, \rho_{p}$ and $\vec{v}_{p}$ denote, respectively, the phase volume fraction, density and velocity vector. $\Gamma_{p}^{\alpha}$ is the diffusion coefficient of species $\alpha$ in phase $p$.

By summing the above equations over all the species $\alpha$, the phase-mass balance equation results:

$$
\frac{\partial\left(r_{p} \rho_{p}\right)}{\partial t}+\nabla \cdot\left(r_{p} \rho_{p} \vec{v}_{p}\right)=\sum_{x} \sum_{q} \sum_{\alpha} \dot{m}_{q p}^{x, \alpha}
$$

The phase-momentum balance is expressed as follows:

$$
\begin{aligned}
\frac{\partial\left(r_{p} \rho_{p} \vec{v}_{p}\right)}{\partial t} & +\nabla \cdot\left(r_{p} \rho_{p} \vec{v}_{p} \vec{v}_{p}\right)+\nabla \cdot\left(r_{p} \overrightarrow{\vec{\tau}}_{p}\right)=-r_{p} \nabla p+r_{p} \rho_{p} \vec{g} \\
& +\sum_{q} r_{p} r_{q} f_{q p}^{\vec{v}_{p}}\left(\vec{v}_{q}-\vec{v}_{p}\right)+\sum_{x} \sum_{q} \sum_{\alpha} \dot{m}_{q p}^{x, \alpha} \vec{v}_{x}
\end{aligned}
$$

The last term represents the momentum source resulting from the transfer of mass; the symbol $x$, when used as a subindex in a variable (for instance $\vec{v}_{x}$ above), refers to the value of the transferred property in the donor phase in mass-exchanging process $x$ (for instance, in particle drying it is the value of the variable in the evaporating phase). $f_{q p}^{\vec{v}}$ is the drag coefficient, $\vec{g}$ is the gravitational acceleration and $\vec{\tau}_{p}$ is the phase stress tensor (to be modeled in case of granular phases). The pressure $p$ is common to all the phases, as it is often assumed in Eulerian formulations.

Phase-energy conservation is formulated as an equation for the phase temperature. The equation neglects compressibility effects and viscous dissipation:

$$
\begin{aligned}
& \frac{\partial\left(r_{p} \rho_{p} C_{p_{p}} T_{p}\right)}{\partial t}+\nabla \cdot\left(r_{p} \rho_{p} C_{p_{p}} \vec{v}_{p} T_{p}\right)+\nabla \cdot\left(r_{p} \kappa_{p} \nabla T_{p}\right)= \\
= & \sum_{q} r_{p} r_{q} f_{q p}^{h}\left(T_{q}-T_{p}\right)+\sum_{x} \sum_{q} \sum_{\alpha} \dot{m}_{q p}^{x, \alpha}\left\{C_{p_{x}} T_{x}+\left(\Delta h_{f_{x}^{\alpha}}^{\alpha}-\Delta h_{f_{p}^{\alpha}}^{\alpha}\right)\right\} \\
+ & \sum_{r} \sum_{\alpha} \dot{\omega}_{p}^{r, \alpha} \Delta h_{f}^{\alpha} .
\end{aligned}
$$

In this equation, $k_{p}$ is the phase conductivity and $f_{q p}^{h}$ is the interphase heat-transfer coefficient. The second term on the RHS (in curly brackets) represents the energy source originating from mass transfer, expressed by means of two contributions: the first one is the interphase transfer of enthalpy due to the transfer of mass (including heterogeneous reactions); the second accounts for the formation enthalpy $\left(\Delta h_{f}\right)$ of the phase species involved in process $x$. As noted earlier, the use of $x$ as a subindex indicates that the property value is that corresponding to 
the donor phase in mass-exchanging process $x$. The last term accounts for the heat released (or absorbed) in homogeneous reactions.

Additionally, the following algebraic equations must be fulfilled (of which the first two are mass-conservation equations):

$$
\begin{aligned}
& \sum_{\alpha} y_{p}^{\alpha}=1 \quad ; \quad \sum_{q} r_{q}=1 \quad ; \\
& f_{q p}^{\vec{v}}=-f_{p q}^{\vec{v}} \quad ; \quad f_{q p}^{h}=-f_{p q}^{h} ; \\
& \sum_{\alpha} \dot{m}_{q p}^{x, \alpha}=0 \quad ; \quad \sum_{\alpha} \dot{\omega}_{p}^{r, \alpha}=0 .
\end{aligned}
$$

Musser et al. [42] have recently discussed the formulation of the multiphase equations and reported some deficiencies in expressions for the source terms reported in literature. They proposed a constitutive equation for enthalpy transfer due to mass transfer and demonstrated that their numerical predictions match experimental data for droplets evaporation and condensation. Our formulation is in agreement with their proposal, except that we use here a conservative expression for the temperature equation (instead of the non-conservative one used by Musser et al.). Our implementation was reported and tested in an earlier paper [16].

\subsection{Hydrodynamic model for multiple granular phases}

The constitutive laws for the solid phases are modeled using the Kinetic Theory of Granular Flows (KTGF). We use the multi-solid approach proposed by Mathiesen et al. [40]; this approach is based on the model developed by Gidaspow (for a single phase solid phase) [25], but extended to handle an arbitrary number of solid phases .

Mathiesen et al. [41] reported a good agreement between measurements of axial and radial segregation in a circulating fluidized bed and computational results obtained using three solid phases with different particle sizes. Moreover, they demonstrated that their multi-solid approach is consistent: the solution for a single solid phase (with a volume fraction $r_{s}$ ) is the same as for $N_{s}$ identical solid phases (each with a volume fraction $r_{s} / N_{s}$ ). We have simplified this formulation so that the same solution is achieved for identical solid phases occupying different volume fractions, thus enhancing the consistency of multi-fluid solution; specifically, we do not use the expression for the binary radial distribution function proposed by Mathiesen et al., but we consider that it is the same as for the single-phase model (as also assumed in the multi-solid model reported by Goldsmith et al. [26]). 
The constitutive equations, detailed in Appendix A, depend on the solid phase granular temperature, $\Theta_{s}$. A transport equation is solved for the granular temperature of each solid phase:

$$
\begin{aligned}
\frac{3}{2}\left[\frac{\partial\left(r_{s} \rho_{s} \Theta_{s}\right)}{\partial t}+\nabla \cdot\left(r_{s} \rho_{s} \vec{v}_{s} \Theta_{s}\right)\right] & = \\
\overrightarrow{\vec{\tau}}_{s} & :: \nabla \vec{v}_{s}+\nabla \cdot\left(r_{s} \kappa_{s}^{\Theta} \nabla \Theta_{s}\right)-\gamma_{s}-3 f_{s z}^{\vec{v}} \Theta_{s} .
\end{aligned}
$$

The solid-solid drag coefficient $f_{s z}^{\vec{v}}$ is modeled applying the KTGF-based proposal of Syamlal [61] (see expression in Appendix A).

Heat transfer among particles of the same phase is taken into account throughout the selfdiffusion term (third term in Equation 4), which includes an effective thermal conductivity $k_{p}$. The thermal interaction during a collision between particles in the configuration is neglected [31], and the solid-solid heat exchange among different solid phases is not modeled. Both are common approaches in Eulerian formulations for particle-particle heat exchange (see, for example, $[5,72])$. Solid-solid heat transfer does not greatly impact our results. Due to the intense mixing processes, the temperature in the bed is rather uniform (the largest temperature difference among solid phases is about $6 \%$ ). In other applications, however, the solid-solid heat transfer could not be negligible and some simplified models are available in the literature $([43,81])$.

For the gas-solid interactions, the drag coefficient $f_{s g}^{v}$ is evaluated using the semi-empirical correlation proposed by Syamlal and O'Brien [63] and the interfacial heat transfer is evaluated using the model developed by Gunn for fluidized beds [29]; both expressions are detailed in Appendix A.

There are more sophisticated solid-drag models that account for the decrease in gas-solid drag forces due to cluster formation within a computational cell. These models, based on the Energy Minimization Multi-Scale (EMMS) theory, are developed for solving relatively dense flows in coarse grids. EMMS approaches were originally formulated for monodisperse flows, and there are few approaches modifying them to consider simultaneously two different types of particles in the emulsion phase $[68,80]$; and only very recently Qin et al. have proposed an extension to polydisperse flows [48].

The fluidized bed solved in this work is relatively dilute and the EMMS drag model has 
not been used. Nevertheless, the solutions obtained in this work present the so-called coreannulus structure, which is claimed to be difficult to capture by conventional drag models when meso-scales effects are significant [47].

The thermo-physical properties of the gas phase are calculated as follows: density follows the ideal gas law; viscosity depends on temperature according to the Sutherland expression; the diffusion coefficients in the species transport equations are calculated as $\Gamma_{g}^{\alpha}=\mu_{g} / S c_{g}$, with the Schmidt number $S c_{g}=0.7$; heat capacity and conductivity are assumed constant. The solid phase conductivity is evaluated as proportional to the gas phase conductivity; in the literature, proportionalities in the range $1<\kappa_{s} / \kappa_{g}<5$ are often suggested [62]; in this work $\kappa_{s}=2.5 \kappa_{g}$

\subsection{Coal-combustion model}

The solid phases are modeled as multicomponent (composed typically of raw coal, char, water and ash) and the mass fraction $y$ for each component $\alpha\left(y_{s}^{\alpha}\right)$ is governed by its transport equation (Equation 1). The model used in this work assumes that the particle size remains constant but its density changes through drying, pyrolysis, gasification and combustion; the particle density is calculated using the density $\rho_{s}^{\alpha}$ of each component:

$$
\frac{1}{\rho_{s}}=\sum_{\alpha} \frac{y_{s}^{\alpha}}{\rho_{s}^{\alpha}}
$$

We have also implemented in our OpenFOAM solver the variant of Spalding's "shadow" method [58] as proposed by Fueyo et al. [22] in order to calculate the evolution of the particle size. The method is based on postulating an additional transport equation for a new phase property that represent the inverse of the phase volume fraction that has disappeared due to mass transfer. The equations for these new phase properties include source terms related to all the processes which do not contribute to a change in particle size. Simulations conducted to compare both approaches (constant size/variable density versus constant density/variable size) show very small differences on both the flow patterns and the flue-gas composition in the fluidized-bed gasifier or in coal combustion in a very dilute one-dimensional stream of hot air.

The drying model assumes that the transfer of the water contained in the solid phase to the gas phase occurs at the boiling temperature. At this temperature, all the heat transferred 
to the particle is used for the phase change, and the solid phase temperature remains constant during the process. The water mass-transfer rate due to particle drying is calculated as:

$$
\dot{m}_{s g}^{\text {drying, } H 2 O}=\frac{f_{s g}^{h}\left(T_{s}-T_{g}\right)+\dot{Q}_{s}^{s u p, H 2 O}}{L_{s g}^{H 2 O}} ;
$$

where $\dot{Q}_{s}^{s u p, H 2 O}$ introduces a correction required in Eulerian frameworks in order to avoid the unrealizable presence of wet particles at a temperature above the boiling point, as proposed by the authors [16]. $\mathrm{L}_{s g}^{\mathrm{H} 2 \mathrm{O}}$ is the specific latent heat of vaporization.

As the fresh fuel particles heat up, the coal undergoes devolatilization to produce volatile gases and char. Devolatilization is represented using a two-competing-reaction model [35]; each reaction being dominant at a different temperature range:

$$
\begin{aligned}
& 1 \text { Raw coal } \stackrel{K_{v 1}}{\longrightarrow} \nu_{v 1} \text { Volatiles }+\left(1-\nu_{v 1}\right) \text { Char } \\
& 1 \text { Raw coal } \stackrel{K_{v 2}}{\longrightarrow} \nu_{v 2} \text { Volatiles }+\left(1-\nu_{v 2}\right) \text { Char }
\end{aligned}
$$

The devolatilization rates are expressed according to an Arrhenius law. For the first reaction, $K_{v 1}=A_{v 1} \exp ^{-T_{v 1} / T} ; A_{v 1}$ and $T_{v 1}$ are, respectively, the pre-exponential factor and the activation temperature, and are detailed in Table 2. For the second reaction, the expressions are similar.

The total mass source (or sink) term in the equations for the volume fractions due to devolatilization is then:

$$
\dot{m}_{s g}^{\mathrm{devol}}=r_{s} \rho_{s}\left(K_{v 1}+K_{v 2}\right) y_{s}^{\mathrm{vol}}
$$

where $y_{s}^{\mathrm{vol}}$ is the mass fraction of volatiles in the solid phase.

The volatile gas is assumed to be made of $\mathrm{H}_{2}, \mathrm{H}_{2} \mathrm{O}, \mathrm{CO}, \mathrm{CO}_{2}, \mathrm{CH}_{4}$ and tar. The composition is estimated following the correlations proposed by Loison and Chauvin [39]. Their model, based on the coal proximate analysis, establishes that the mass fraction of the gaseous species $\alpha$ in the volatile gas $\left(Y_{\mathrm{vol}}^{\alpha}\right)$ depends only on the mass fraction of the volatile matter in the coal on a dry and ash-free basis (daf), $Y_{s(\mathrm{daf})}^{\mathrm{vol}}$ : 


$$
\begin{gathered}
Y_{\mathrm{vol}}^{\mathrm{H}_{2}}=0.157-0.869\left(Y_{s(\mathrm{daf})}^{\mathrm{vol}}\right)+1.338\left(Y_{s(\mathrm{daf})}^{\mathrm{vol}}\right)^{2} \\
Y_{\mathrm{vol}}^{\mathrm{H}_{2} \mathrm{O}}=0.409-2.389\left(Y_{s(\mathrm{daf})}^{\mathrm{vol}}\right)+4.554\left(Y_{s(\mathrm{daf})}^{\mathrm{vol}}\right)^{2} \\
Y_{\mathrm{vol}}^{\mathrm{CO}}=0.423-2.653\left(Y_{s(\mathrm{daf})}^{\mathrm{vol}}\right)+4.845\left(Y_{s(\mathrm{daf})}^{\mathrm{vol}}\right)^{2} \\
Y_{\mathrm{vol}}^{\mathrm{CO}_{2}}=0.135-0.900\left(Y_{s(\mathrm{daf})}^{\mathrm{vol}}\right)+1.906\left(Y_{s(\mathrm{daf})}^{\mathrm{vol}}\right)^{2} \\
Y_{\mathrm{vol}}^{\mathrm{CH}_{4}}=0.201-0.469\left(Y_{s(\mathrm{daf})}^{\mathrm{vol}}\right)+0.241\left(Y_{s(\mathrm{daf})}^{\mathrm{vol}}\right)^{2} \\
Y_{\mathrm{vol}}^{\mathrm{tar}}=-0.325+7.279\left(Y_{s(\mathrm{daf})}^{\mathrm{vol}}\right)-12.844\left(Y_{s(\mathrm{daf})}^{\mathrm{vol}}\right)^{2}
\end{gathered}
$$

The rate of an heterogeneous reaction $r$ between the char in the solid phase $s$ and a species $\alpha$ in the gas phase $g$ is assumed to be governed by the intrinsic kinetic rate $\left(K_{r}\right.$, expressed by an Arrhenius equation) and the diffusion resistance of the reacting gas species, $D_{\alpha r}$.

The rate of mass transfer due to the heterogeneous reaction $r$, which is also the rate of char consumption due to such reaction, is:

$$
\dot{m}_{s g}^{r}=\nu_{\mathrm{char}, r} S_{s} p_{\alpha} \frac{D_{\alpha r} K_{r}}{D_{\alpha r}+K_{r}}
$$

where $\nu_{\mathrm{char}, r}$ is the char stoichiometric coefficient, $S_{s}$ is the solid phase surface area (calculated as $6 r_{s} / d_{s}$ ) and $p_{\alpha}$ is the partial pressure of the reacting gas species $\alpha$ (for example, $\mathrm{O}_{2}$ in the char oxidation reaction). The expressions for $D_{\alpha r}$ and $K_{r}$ are the following:

$$
D_{\alpha r}=\operatorname{Sh}_{g} \frac{\Gamma_{\alpha}}{d_{s}} \frac{W_{\alpha}}{\nu_{\alpha, r}} \frac{1}{R T_{g}} \quad ; \quad K_{r}=A_{r} T^{n_{r}} \exp ^{-T_{r} / T_{s}} \quad ;
$$

Here $\mathrm{Sh}_{g}$ is the Sherwood number; $\Gamma_{\alpha}$ is the species diffusion coefficient; $R$ is the universal gas constant; and $W_{\alpha}$ and $\nu_{\alpha, r}$ are respectively the molecular weight and the stoichiometric coefficient for gas species $\alpha$ involved in the heterogeneous reaction $r$. The reaction coefficients $A_{r}, n_{r}$ and $T_{r}$ are given in Table 2 .

The gas released from the particle processes reacts with the fluidizing gas. The chemical mechanism used for modeling the homogeneous reactions is integrated using the open-software Cantera [1], that has been coupled to the OpenFOAM solver by the authors.

Coal combustion is described by the chemical mechanisms summarized in Table 1 [19]. They include heterogeneous reactions for char oxidation and for gasification with $\mathrm{H}_{2} \mathrm{O}$ and $\mathrm{CO}_{2}$; and homogeneous reactions in the fluidizing gas: the water-gas shift reaction (R6) and 


\begin{tabular}{|c|c|}
\hline Reaction & Raw coal: Char + Volatile $+\mathrm{H}_{2} \mathrm{O}+$ Ash \\
\hline & Drying \\
\hline \multirow[t]{2}{*}{$\mathrm{R} 1$} & $\mathrm{H}_{2} \mathrm{O}(\mathrm{l}) \rightarrow \mathrm{H}_{2} \mathrm{O}(\mathrm{g})$ \\
\hline & Devolatilization \\
\hline $\mathrm{R} 2^{1}$ & 1 Raw coal $\rightarrow \nu_{v 1}$ Volatiles $+\left(1-\nu_{v 1}\right)$ Char $\quad ; \quad \nu_{v 1}=0.5$ \\
\hline \multirow[t]{3}{*}{$\mathrm{R} 2^{2}$} & 1 Raw coal $\rightarrow \nu_{v 2}$ Volatiles $+\left(1-\nu_{v 2}\right)$ Char $\quad ; \quad \nu_{v 2}=1$ \\
\hline & Volatiles $(\mathrm{g}): \mathrm{H}_{2}(\mathrm{~g}), \mathrm{H}_{2} \mathrm{O}(\mathrm{g}), \mathrm{CO}(\mathrm{g}), \mathrm{CO}_{2}(\mathrm{~g}), \mathrm{CH}_{4}(\mathrm{~g}), \operatorname{tar}(\mathrm{g})$ \\
\hline & Heterogeneous reactions \\
\hline $\mathrm{R} 3$ & $\mathrm{C}(\mathrm{s})+\mathrm{r} \mathrm{O}_{2} \rightarrow(2 \mathrm{r}-1) \mathrm{CO}+2(1-\mathrm{r}) \mathrm{CO}_{2} ; \mathrm{r}=0.68$ \\
\hline $\mathrm{R} 4$ & $\mathrm{C}(\mathrm{s})+\mathrm{H}_{2} \mathrm{O} \rightarrow \mathrm{CO}+\mathrm{H}_{2}$ \\
\hline \multirow[t]{2}{*}{$\mathrm{R} 5$} & $\mathrm{C}(\mathrm{s})+\mathrm{CO}_{2} \rightarrow 2 \mathrm{CO}$ \\
\hline & Homogeneous reactions and reaction rates $R$ \\
\hline$R 6^{\mathrm{f}}$ & $\mathrm{CO}+\mathrm{H}_{2} \mathrm{O} \rightarrow \mathrm{H}_{2}+\mathrm{CO}_{2} ; R=K C_{\mathrm{CO}} C_{\mathrm{H}_{2} \mathrm{O}}$ \\
\hline $\mathrm{R} 6^{\mathrm{b}}$ & $\mathrm{H}_{2}+\mathrm{CO}_{2} \rightarrow \mathrm{CO}+\mathrm{H}_{2} \mathrm{O} ; R=K C_{\mathrm{H}_{2}} C_{\mathrm{CO}_{2}}$ \\
\hline $\mathrm{R} 7$ & $\mathrm{CO}+0.5 \mathrm{O}_{2} \rightarrow \mathrm{CO}_{2} ; R=K C_{\mathrm{CO}} C_{\mathrm{O}_{2}}^{1 / 4} C_{\mathrm{H}_{2} \mathrm{O}}^{1 / 2}$ \\
\hline $\mathrm{R} 8$ & $\mathrm{H}_{2}+\mathrm{O}_{2} \rightarrow \mathrm{H}_{2} \mathrm{O} ; R=K C_{\mathrm{H}_{2}} C_{\mathrm{O}_{2}}$ \\
\hline $\mathrm{R} 9$ & $\mathrm{CH}_{4}+2 \mathrm{O}_{2} \rightarrow 2 \mathrm{H}_{2} \mathrm{O}+\mathrm{CO}_{2} ; R=K C_{\mathrm{CH}_{4}}^{0.7} C_{\mathrm{O}_{2}}^{0.8}$ \\
\hline
\end{tabular}

Table 1: Chemical mechanisms 


\begin{tabular}{lcccc}
\hline Reaction & Type & $A_{r} /$ (units) & $n_{r}$ & $T_{r} / \mathrm{K}$ \\
\hline R2 & Devolatilization & $2.0 \times 10^{5} /(1 / \mathrm{s})$ & 0 & $1.26 \times 10^{4}$ \\
R2 $^{2}$ & Devolatilization & $1.3 \times 10^{7} /(1 / \mathrm{s})$ & 0 & $2 \times 10^{4}$ \\
\hline R3 & Heterogeneous & $17.9 \times 10^{0} /\left(\mathrm{kg} / \mathrm{m}^{2} / \mathrm{s}\right)$ & 0 & -13750 \\
R4 & Heterogeneous & $5.95 \times 10^{5} /\left(\mathrm{kg} / \mathrm{m}^{2} / \mathrm{s}\right)$ & 0 & -13650 \\
R5 & Heterogeneous & $3.92 \times 10^{0} / \mathrm{kg} / \mathrm{m}^{2} / \mathrm{s}$ & 0 & -26927 \\
\hline R6 & Homogeneous & $2.780 \times 10^{3} /\left(\mathrm{kg} / \mathrm{m}^{3} / \mathrm{s}\right)$ & 0 & -1510 \\
R6 & Homogeneous & $1.049 \times 10^{5} /\left(\mathrm{kg} / \mathrm{m}^{3} / \mathrm{s}\right)$ & 0 & -5478 \\
R7 & Homogeneous & $1.000 \times 10^{15} /\left(\mathrm{kg} / \mathrm{m}^{3} / \mathrm{s}\right)$ & 0 & -20119 \\
R8 & Homogeneous & $2.196 \times 10^{12} /\left(\mathrm{kg} / \mathrm{m}^{3} / \mathrm{s}\right)$ & 0 & -13127 \\
R9 & Homogeneous & $3.552 \times 10^{14} /\left(\mathrm{kg} / \mathrm{m}^{3} / \mathrm{s}\right)$ & -1 & -24343 \\
\hline
\end{tabular}

Table 2: Kinetic parameters of the chemical reactions (see [74] for full description of the chemical system for the homogeneous reactions)

the oxidation of $\mathrm{CO}, \mathrm{H}_{2}$ and $\mathrm{CH}_{4}(\mathrm{R} 7, \mathrm{R} 8$ and $\mathrm{R} 9)$. Table 2 presents the kinetic parameters used in this work for the heterogeneous and homogeneous reactions; these have been taken from [7] for the heterogeneous reactions and from [74] for the homogeneous reactions.

\section{Numerical algorithm}

The unsteady Eulerian-Eulerian conservation equations for multiphase flows presented above, and their closure relationships, are solved using an IPSA-like consistent and conservative algorithm developed and implemented for inert flows in the OpenFOAM software by the authors [15]. An excerpt from the validation of this algorithm for bed hydrodynamics is shown in Appendix C.

The algorithm is a consistent extension to multiphase flows of the so-called Momentum Interpolation (MI) technique. This consistent extension prevents the formation of chessboardlike fields in flows with strong phase segregation.

In previous paper [16], in addition to our reporting the performance of the algorithm for multicomponent and multiphase flows with heat and mass transfer (and variable density), we provided a supplementary test case for a bubbling fluidized bed (included as Supplementary 


\begin{tabular}{lc} 
Bed operational parameters & \\
\hline Coal mass-flow-rate $/ \mathrm{kg} \mathrm{h}^{-1}$ & 8 \\
Air mass-flow-rate / $\mathrm{kg} \mathrm{h}^{-1}$ & 21.9 \\
Steam mass-flow-rate / kg h & 4.6 \\
Temperature at feeding point / K & 300 \\
Temperature at bottom inlet / K & 693 \\
Fluidizing velocity / $\mathrm{m} \mathrm{s}^{-1}$ & 0.41 \\
\hline
\end{tabular}

Table 3: Operational parameters

Material). Phase segregation, particle heating and the phase change of water at the saturation temperature were all realistically predicted.

To model combustion in fluidized beds, improvements have been introduced in the present work to handle mass transfer and variable density, and to enhance the numerical coupling among the phases. The resulting discretized equation for the pressure equation is detailed in Appendix B. We use a sequential, dual-step procedure for solving the unsteady, coupled equations governing multiphase flows as detailed in [15], but including for the problem at hand an additional loop for solving the equation for the phase temperature, gas species and particle components.

\section{Configuration of the bubbling fluidized bed gasifier}

The bubbling fluidized bed chosen for the present investigation is part of a pilot plant designed and built for studying the gasification of a Colombian coal (Ocampo et al. [44] and Chejne and Hernández [7]). This is a cylindrical reactor, with a height of $2 \mathrm{~m}$ and a diameter of $0.22 \mathrm{~m}$; a feeding port is located $0.3 \mathrm{~m}$ above the distributor plate. The fluidizing gas is air and steam. Table 3 presents the operational parameters, and Figure 1 (a) a schematic of the riser configuration.

The gasifier riser is modeled using a two-dimensional domain $0.22 \times 2 \mathrm{~m}^{2}$, with 2200 cells, 100 in the axial direction and 22 in the transversal direction.

The walls are assumed to be adiabatic, and no-slip conditions are imposed for the phase velocities. At the outlet, the pressure is set to the atmospheric pressure, and zero-gradient 


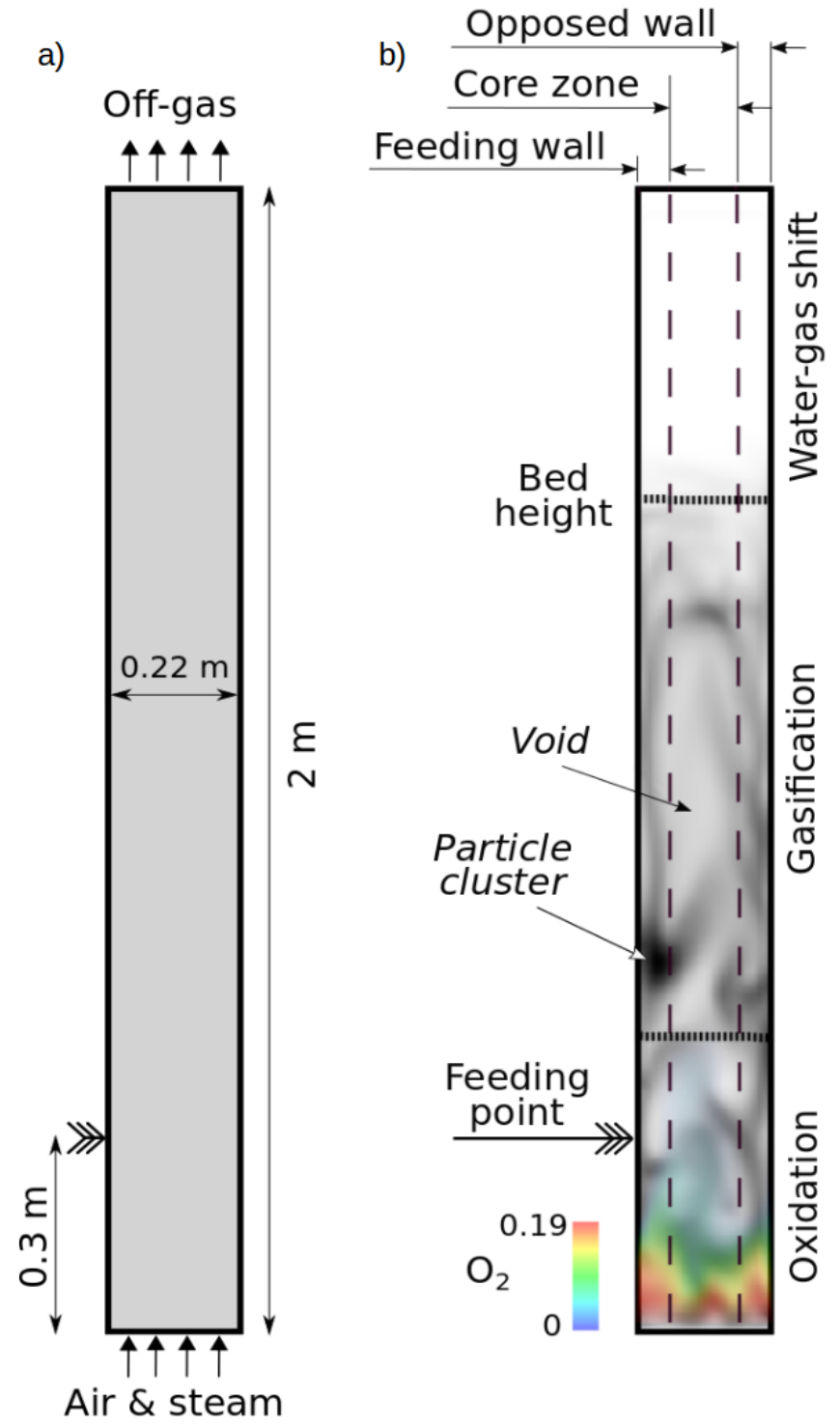

Figure 1: Schematic of the fluidized bed (a) and illustration of the several zones along the riser (b): $\mathrm{O}_{2}$ mass-fraction contours (color legend) superimposed on gas volume fraction contours (gray shades) 
Main solids characteristics

\begin{tabular}{lcccccc}
\hline & Limestone & Coal & \multicolumn{5}{c}{ Coal components } \\
\hline & Mean & Mean & Coal & Char & Ash & Water \\
\cline { 5 - 8 } & 1.0 & 1.0 & 0.418 & 0.541 & 0.015 & 0.026 \\
Mass fraction $/ \mathrm{kg} / \mathrm{kg}$ & 2700 & 635 & 1250 & 450 & 1250 & 1000 \\
Density $/ \mathrm{kg} / \mathrm{m}^{3}$ & 600 & 620 & - & - & - & - \\
Diameter $/ \mu \mathrm{m}$ & 840 & 1600 & - & - & - & - \\
Heat capacity / J/kg/K & 1.33 & 0.107 & - & - & - & - \\
Conductivity / $/ \mathrm{W} / \mathrm{m} / \mathrm{K}$ & & & & &
\end{tabular}

Coal sizes

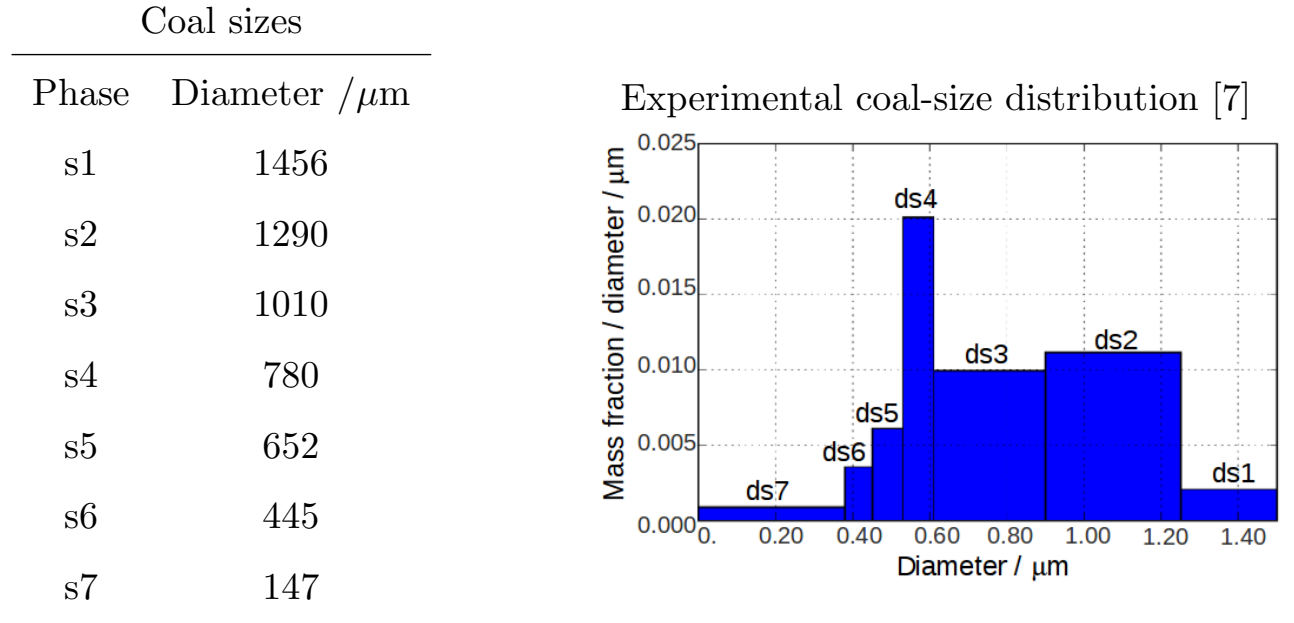

Table 4: Main solid characteristics and coal size-distribution 
boundary conditions are used for the rest of the variables.

As an illustration, Figure 1 (b) presents a snapshot of the bubbling bed gasifier from the present model. We define three longitudinal zones in the riser, as shown in the figure: one along the feeding wall, a core zone and one along the opposite wall. These zones will be indicative of the typical core-annulus pattern in risers, and will be instrumental in presenting the results below.

Figure 1 also illustrates three zones where, as will be shown, three important reactions predominantly take place: char oxidation in the lower region; char gasification once oxygen is consumed; and, in the freeboard, the water-gas-shift reaction in the gas phase that continues to produce hydrogen.

Table 4 presents the main coal and limestone characteristics. Coal is considered a variabledensity phase with four constituent components (raw coal, water, char, ash); limestone is modeled as inert, single-component phase. The initial mass fractions of the coal-particle components are those from the proximate analysis [44].

The experimental work uses a coal particle-size-distribution with seven diameters [7]. From this experimental distribution, three cases are defined for the present numerical investigation: one with the seven experimental coal-size bins, another one with just one average one, and a third case with a narrower distribution with three coal diameters. The mean size is the same in the three cases, and equal to the experimental one, $d=620 \mu \mathrm{m}$. The seven-phase particle-size distribution used in the calculations is shown in Table 4; it is the same as the one reported in the experimental work [7]. For the sake of brevity, results for the three coal sizes are not included in the present paper (these are reported in the $\mathrm{PhD}$ dissertation by A. Sánchez Insa $[50])$.

\subsection{Numerical details}

The simulation of the experimental bed is started as a limestone bed with a height of $1 \mathrm{~m}$ and a solids volume fraction $r_{s 0}=0.24$, where fresh coal is fed. This initial bed contains also some completely-converted (ash-only) coal, with a volume fraction $r=0.12$. All the phases are initially at rest and at temperature of $1100 \mathrm{~K}$.

The transient evolution of the fluidized bed is solved using our CIPSA algorithm (described in Section 3), using a time step of $\Delta t=5 \times 10^{-4} \mathrm{~s}$. During the solver inner iterations for each 
time step, the residuals decrease by 5 to 10 orders of magnitude. From the initial state (bed at rest), the gasifier is simulated for $t=120 \mathrm{~s}$ of real time.

Results show that after the first $100 \mathrm{~s}$ the flow is statistically steady-state. Time-averaged variables are obtained using the latest $10 \mathrm{~s}$ of simulation with a sampling frequency of $50 \mathrm{~Hz}$.

Some additional post-processing is conducted for result analysis. The variables are averaged in the cross-stream section to analyze their vertical evolution in the bed. Additionally, this cross-section averaging is also conducted over each of the three longitudinal zones indicated in Figure 1. The cross-section averaging allows the quantification of the lateral distribution across the riser. The lateral zones (feeding wall and opposite wall) have a width of $0.04 \mathrm{~m}$.

The complete simulation takes approximately 4 days on a single core of an Intel Core i7 920 at $2.67 \mathrm{GHz}$ (although the developed Eulerian-Eulerian model is run in parallel on several cores). To reduce the computing time, the integration of the chemical mechanism describing the homogeneous reactions (which is very stiff) is activated only during the last $t=20 \mathrm{~s}$ of real time. The calculation of this time interval represents around $70 \%$ of the total computing time. Of course, this calculation could be optimized in a number of ways, such as tabulating the chemistry, but this optimization has not been addressed in this work.

This computational cost may be compared with the requirements of Lagrangian approaches (briefly described in Section 1). As reviewed by Zhong et al. [79], the computing time necessary to perform the Eulerian-Lagrangian (BCFD-DEM) simulation for non-reacting flow is about $2-4$ orders of magnitude larger than an Eulerian-Eulerian simulation $([13,32])$. Ku et al. [36] recently reported that 14 days worth of running time on a 16-core Intel node were needed to compute $20 \mathrm{~s}$ real time of simulation of a lab-scale biomass gasifier, discretized with 1725 cells and solved using their own CFD-DEM model, also implemented in OpenFOAM. Zhong et al. [79] estimate that the time for simulating the reactive bed via the particle-in-cell Lagrangian MP-PIC model is twice as expensive as the present Eulerian-Eulerian simulation.

\section{Results: Effect of polydispersion on the bed flow patterns}

In this section we investigate whether, and how, the representation of coal as a polydisperse phase affects the flow patterns in the reactor. In order to discriminate the effects of combustion from those of particle polydispersion, the bed has been also solved with the same inlet and 
(a) Monodisperse coal

- Limestone $d_{s 0}=600 \mu \mathrm{m}$

- Coal

$d_{s 1}=620 \mu \mathrm{m}$

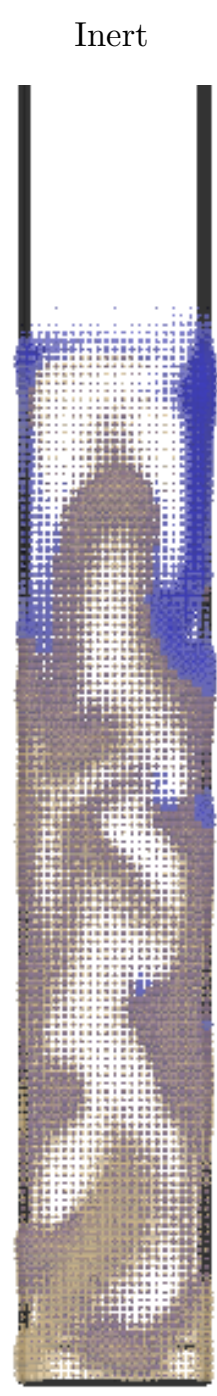

Combusting

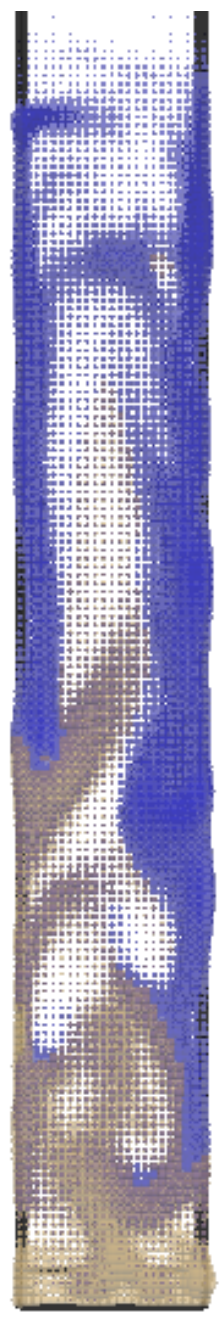

(b) Multidisperse coal

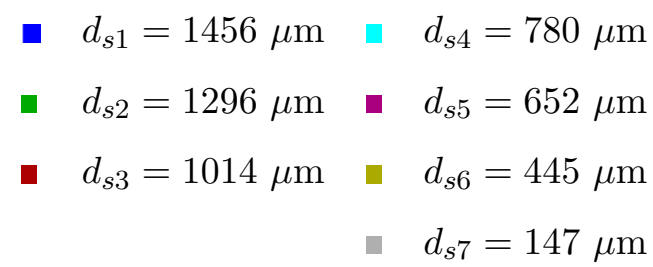

Inert

Combusting
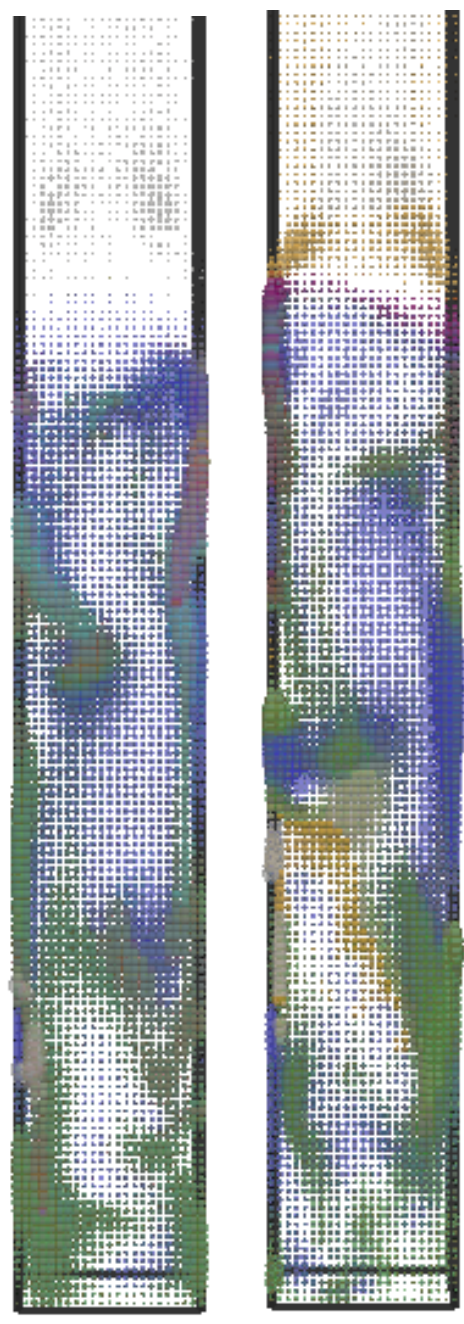

Figure 2: Spatial distribution of each phase at $t=120 \mathrm{~s}$ for monodisperse-coal (left frame, a) and polydispersecoal (right frame, b) beds, and for the inert and combusting cases. The solid phases are shown as dots with a size proportional to the number density of phase particles. For clarity, limestone is not shown in the polydisperse cases 
initial conditions but assuming that all the solids are inert (by numerically deactivating the coal devolatilization and combustion models).

The snapshots shown in Figure 2 illustrate the hydrodynamics of fluidization in the monodisperse (a) and polydisperse (b) coal beds. (In all cases, monodisperse limestone particles are also present, but not shown for the polydisperse cases for clarity), as indicated in Table 4; their size is similar to the monodisperse coal, but their density is nearly four times as large as that of raw coal or twice as large as that of ash). To present a clear but compact picture, we represent the phase as spheres; the size of each sphere is proportional to the local number of particles, and is normalized for each phase.

As supplementary data we present a video with the evolution of the volume fraction of each solid phase for the combusting and polydisperse case. Figure 3 shows a frame from this video.
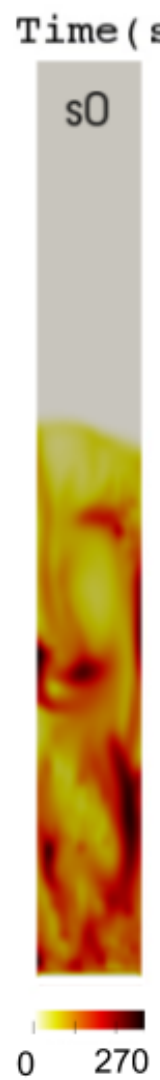

\section{: 119.950}

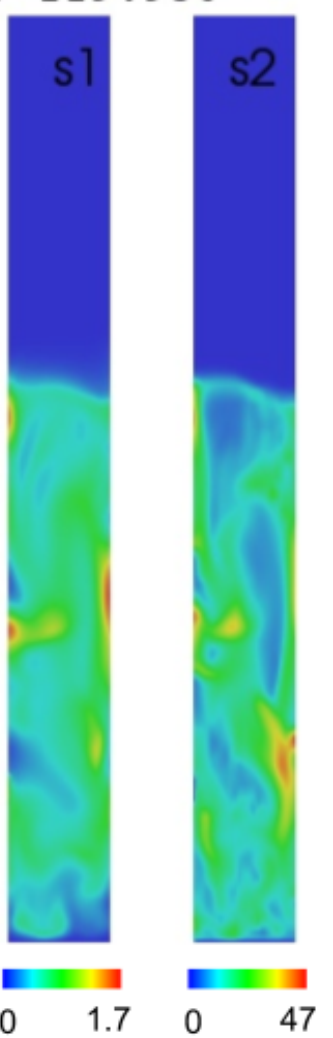

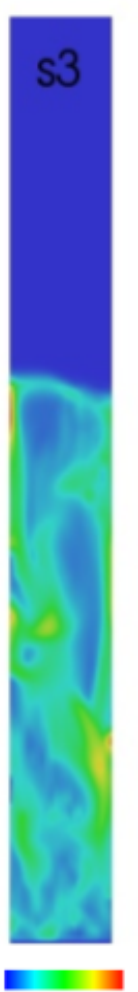

023
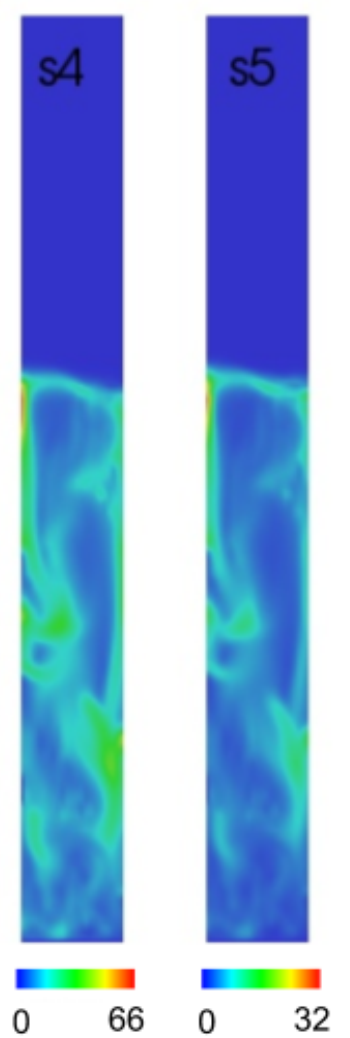

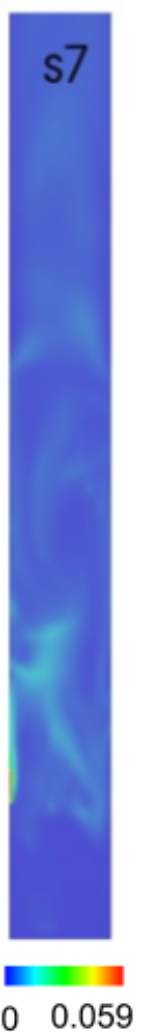

Figure 3: Volume-fraction $\left(10^{3} \times r_{s}\right)$ contours for each solid phase in the combusting and polydisperse case. (Available as video with the supplementary material) 
As will be further supported in subsequent subsections, the model correctly captures the vertical and lateral segregation trends reported in the literature. For the monodisperse coal, and in both the inert and combusting case, vertical segregation of coal and limestone is apparent in the results presented in Figure 2 (a) and (b), with the (heavier) limestone particles concentrating preferentially at the bed bottom layer while the (lighter) coal particles moving towards to top. In the middle of the bed, the both phases are present with similar volume fractions (normalized with respect to the initial ones). In the horizontal, or cross-flow, direction the so-called core-annulus structure is observed: dilute, rapidly-moving bubbles ascend through the bed core, whereas denser clusters of particles descend close to the bed walls.

For the coal polydisperse cases, vertical segregation is very apparent in Figure 2 for coal phases with smaller sizes; the smallest particles are clearly elutriated out the bed. The lateral distribution of the largest particles, however, is remarkably more uniform.

\subsection{Vertical distribution}

In this section, we show that our model corroborates existing knowledge about axial segregation for beds with two particle sizes, and also the scarcely-reported fluidization behavior for polydisperse, continuously-distributed particles.

As summarized by Chew et al. [12], a wider size distribution generally increases segregation: finer and coarser particles tend to segregate, respectively, to the top and the bottom of the

(a) Inert case

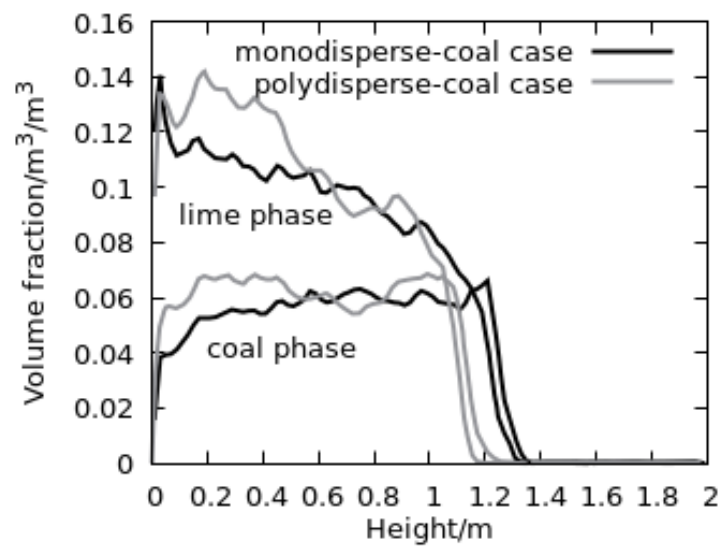

(b) Combusting case

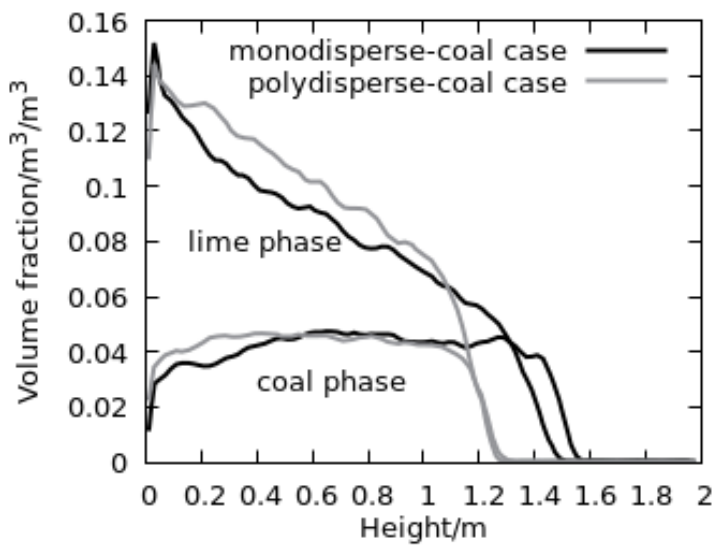

Figure 4: Vertical profiles of solid-phase volume-fraction in the bed for an inert (a) or combusting (b) bed, modeled with one and with seven coal sizes 
(a) Inert case

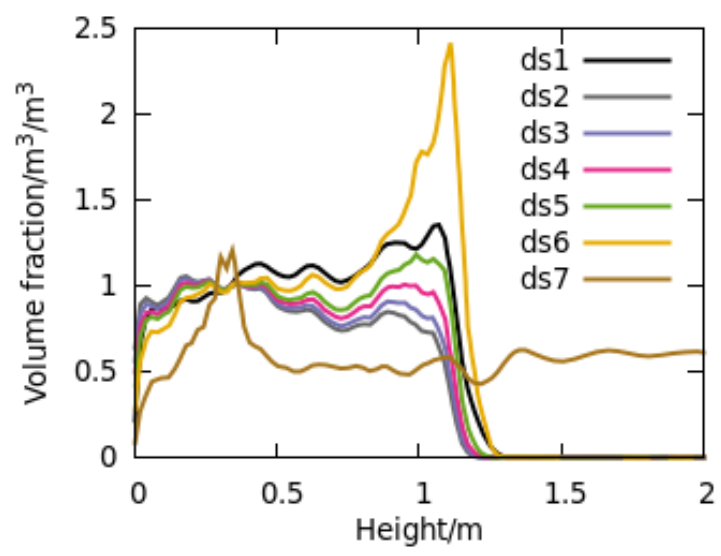

(b) Combusting case

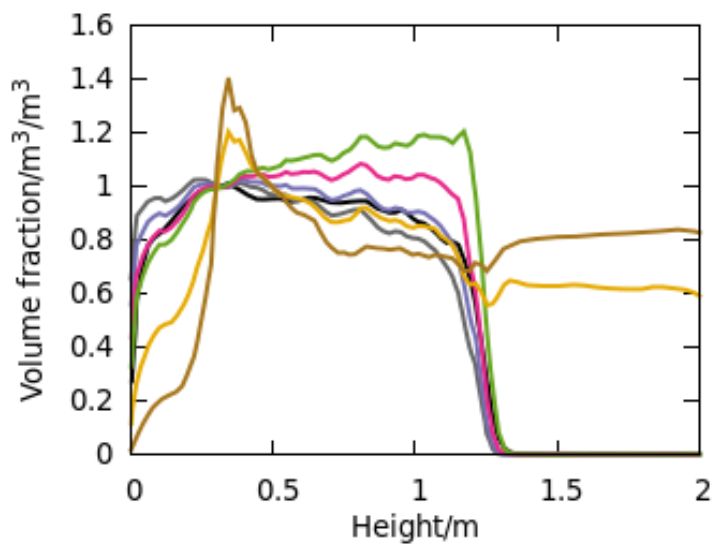

Figure 5: Vertical profiles of each phase volume fraction (normalized with their values at the feeding height) in the inert (a) and reactive (b) beds. See phase diameters in Table 4.

reactor, while the shape of the particle distribution is largely preserved in the middle of the reactor. (Our results for a coarser distribution with three sizes, not shown in this paper, support also these segregation trends [50]).

Figure 4 shows the evolution with height of the limestone and coal volume-fractions, averaged in the cross-section. (For the polydisperse-coal cases, the average of the total volume fraction is presented).

As expected, the limestone volume fraction decreases with height. The bed is slightly shorter for a coal-size distribution, probably due to the uneven segregation of the coal phases and to the elutriation of the smaller particles; however, for the same size distribution, the reactive bed is taller than the inert one. The (average) temperatures are not too different in the inert and reactive reactors, and thus this bed expansion is brought about by changes in the particle density during coal combustion.

The evolution with height of the volume fraction for each of the coal phases, shown in Figure 5, allows to further study their vertical segregation. Chew et al. [12] reported also, in their inert bed, an unexpected behavior of the largest particles in a log normal distribution, which in our case would correspond to the poor fluidization of the coal phase with the largest size, $d_{s 1}$, Figure 5. (We should note that the configuration of Chew et al. [12] is composed primarily of Geldart B particles, while our d1-d3 phases are Geldart D and our d4-d7 phases are Geldart B). Our reactive calculations further indicate that this trend also holds for the 
(a) Monodisperse coal

Inert

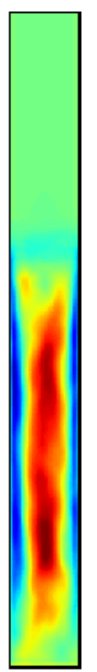

Combusting

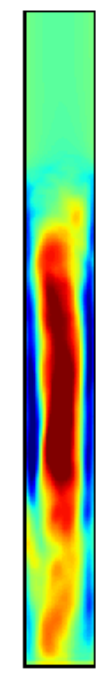

$$
U_{y}
$$

$(m / s)$

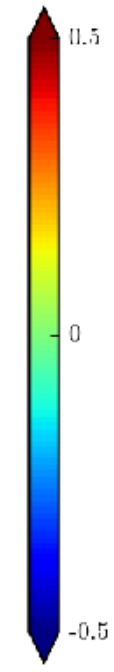

(b) Polydisperse coal

Inert

Combusting
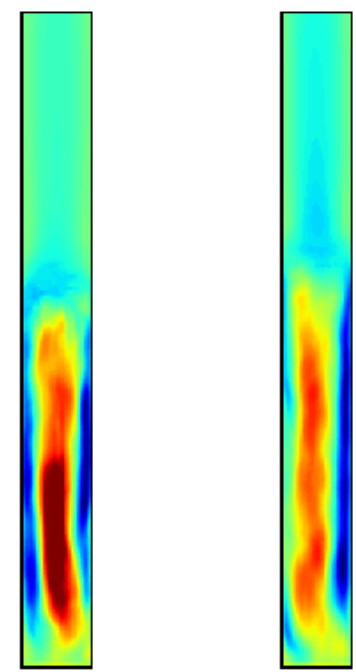

Figure 6: Time-averaged contours of limestone vertical velocity $(\mathrm{m} / \mathrm{s})$

combusting bed.

The effects of polydispersion on particle distribution in the bed are similar for the inert and combusting beds. Relative to the distribution at the feeding height, the fraction of larger particles increases at the bottom layer and decreases at the top layer, except for the elutriated sizes and for the more uniformly distributed largest sizes. The very large coal particles (six times as heavy as the limestone particles) are not thrown out of the bubbles, and scarcely take part in the hydrodynamics of fluidization: as can be seen in the snapshots shown in Figures 2 and 11, large coal particles are the only ones present in significant amounts inside the bubbles in the core, especially in the middle and top zones.

In the reactive bed, not only the finest but also the second smallest sizes are elutriated.

\subsection{Lateral distribution}

The lateral flow pattern presents the so-called core-annulus structure (Figures 6 and 7), characterized by a central, relatively dilute flow moving upwards, surrounded by a denser flow moving downwards along the external wall; this characteristic structure has been reported in the literature, see for instance [25].

Remarkably, in the case of the reactive and polydisperse bed, the symmetry is not so 
(a) Inert and monodisperse case

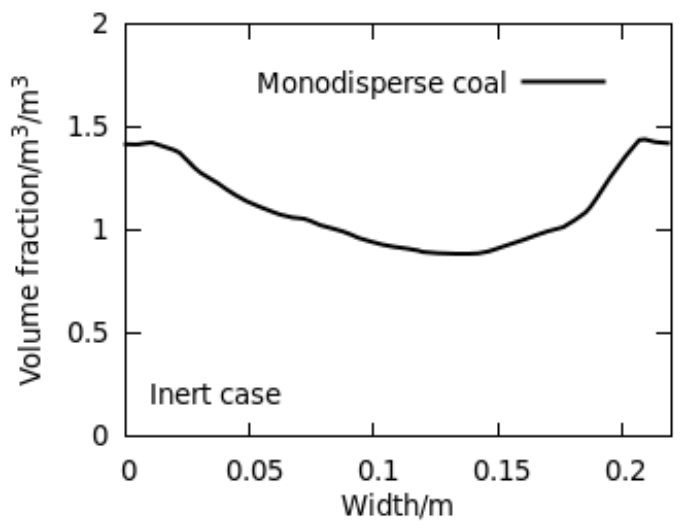

(c) Combusting and monodisperse case

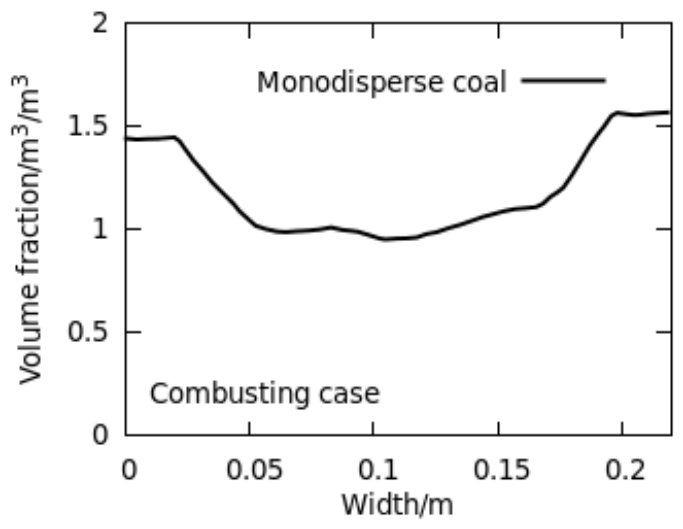

(b) Inert and polydisperse case

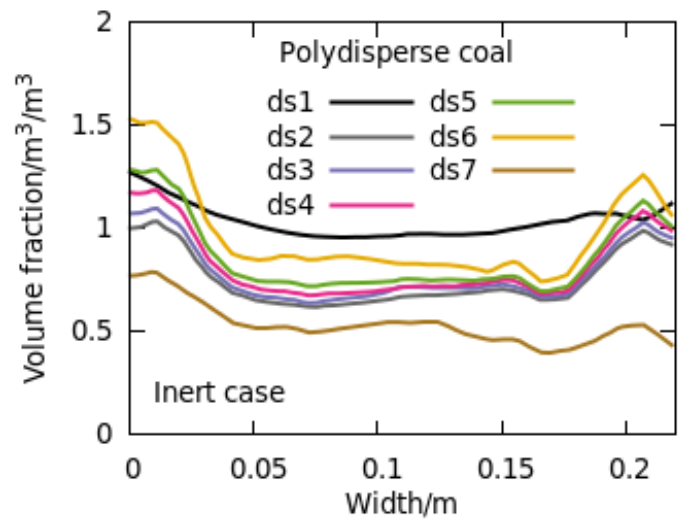

(d) Combusting and polydisperse case

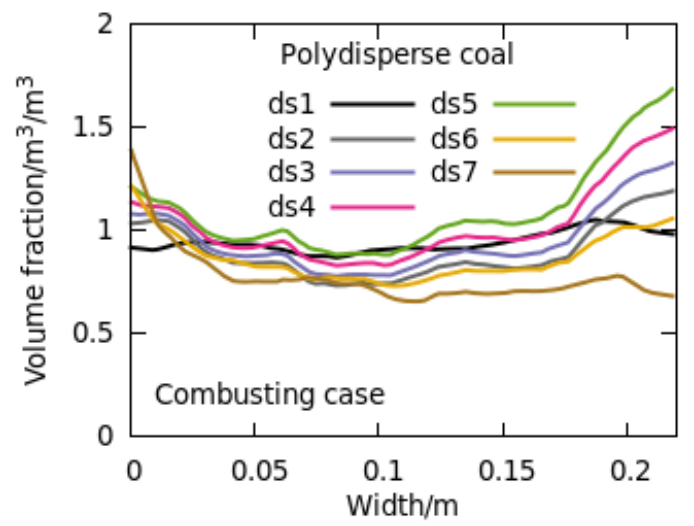

Figure 7: Horizontal profiles of coal-phase volume-fraction (normalized with the value at the feeding height) at a height of $0.7 \mathrm{~m}$ in the hot $(\mathrm{a}, \mathrm{b})$ and reactive $(\mathrm{c}, \mathrm{d})$ beds, and for monodisperse $(\mathrm{a}, \mathrm{c})$ and polydisperse (b,d) coal particles 
Time(s): 119.990
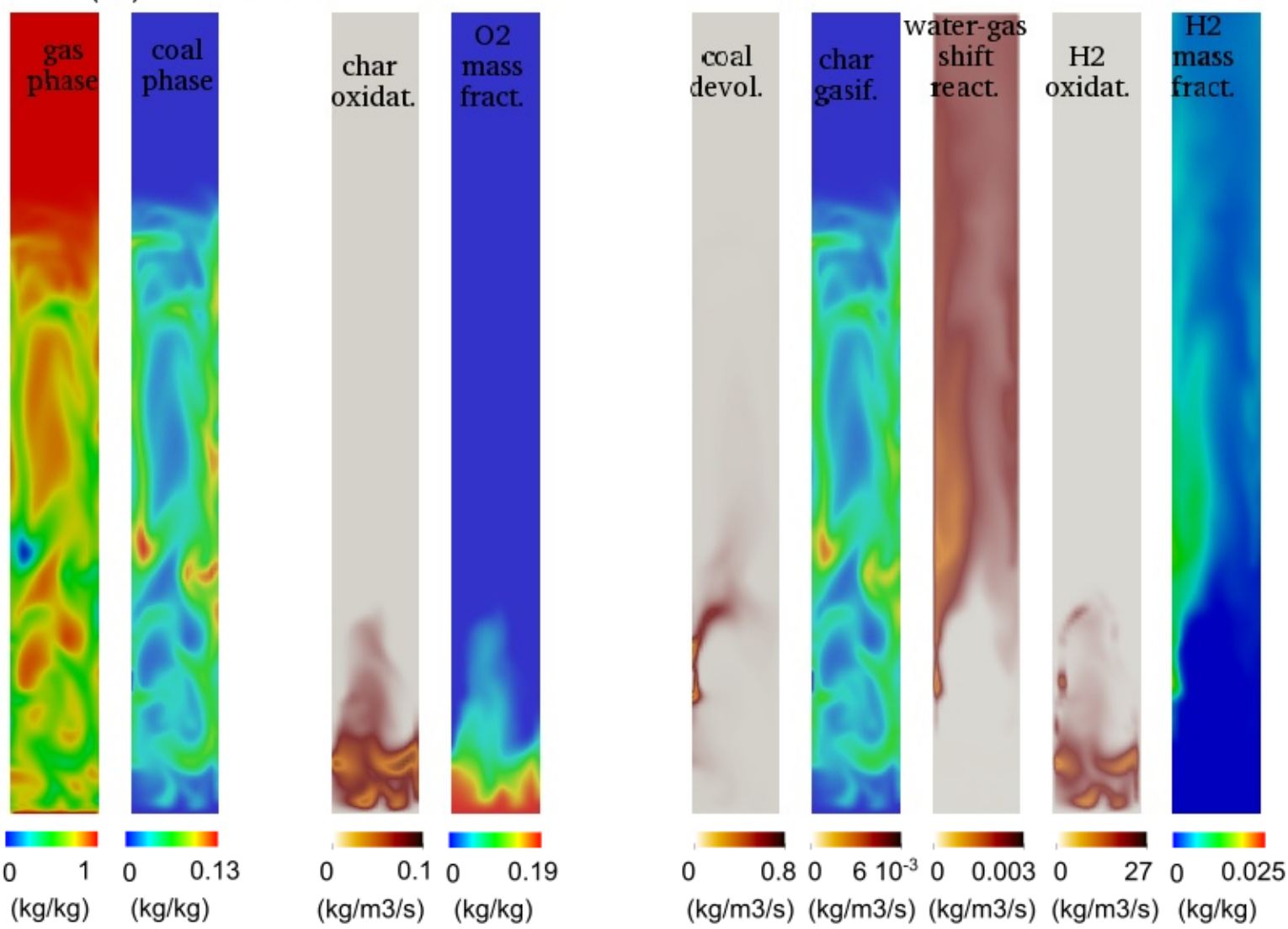

Figure 8: Monodisperse-coal bed. Contours of limestone and coal volume fractions, the oxygen and hydrogen mass fractions and reaction rates of: char oxidation and gasification, devolatilization, hydrogen oxidation and water-gas shift reaction. (Available as video with the supplementary material) 431 gas bubbles. 
Time(s): 119.950
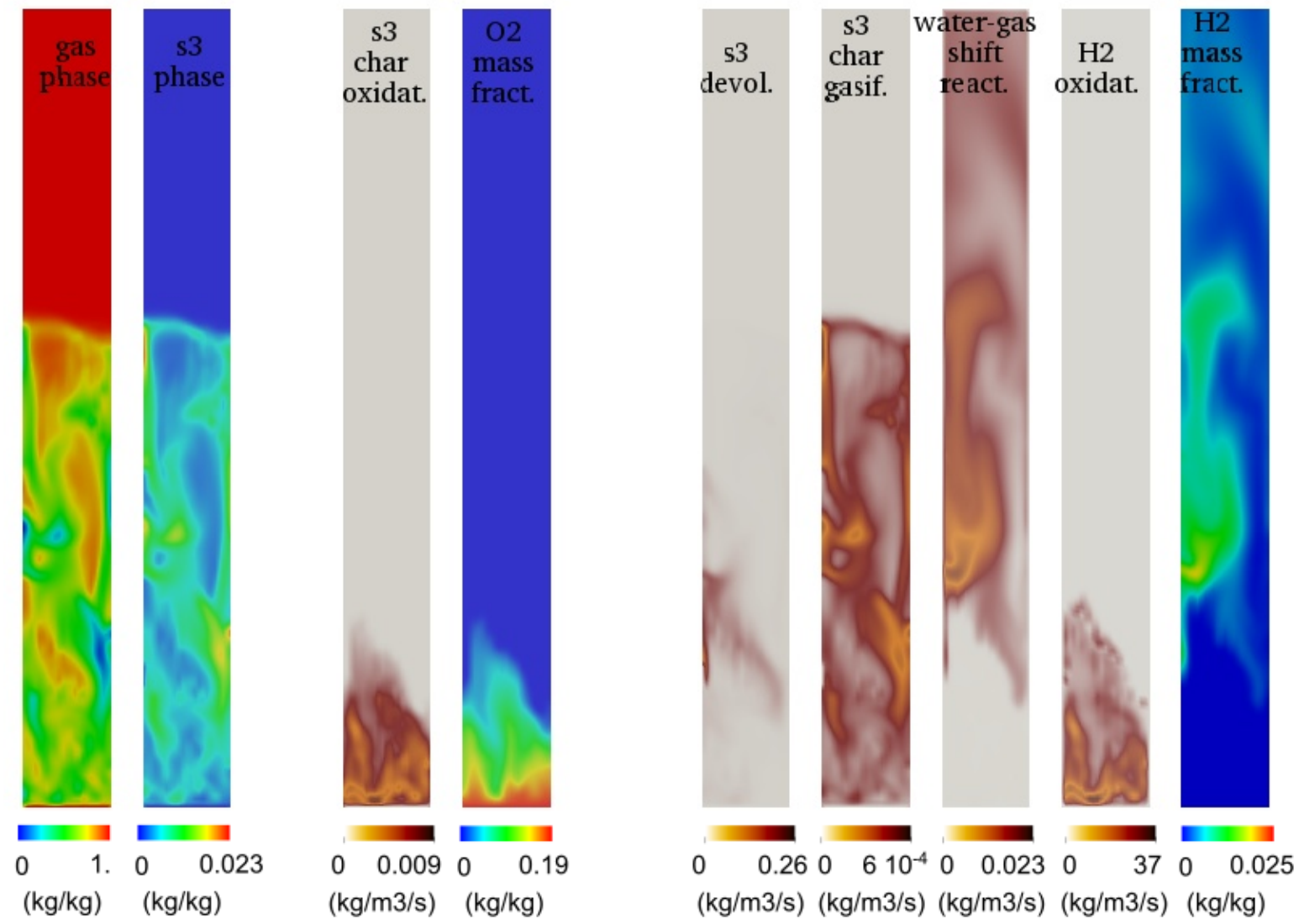

Figure 9: Polydisperse-coal bed. Contours of limestone and $s 3$-coal-phase volume fractions, of mass fractions of oxygen and hydrogen, and of reaction rates of char oxidation and gasification of $s 3$-coal phase, devolatilization, hydrogen oxidation and water-gas shift reaction. (Available as video with the supplementary material) 
(a) Monodisperse coal

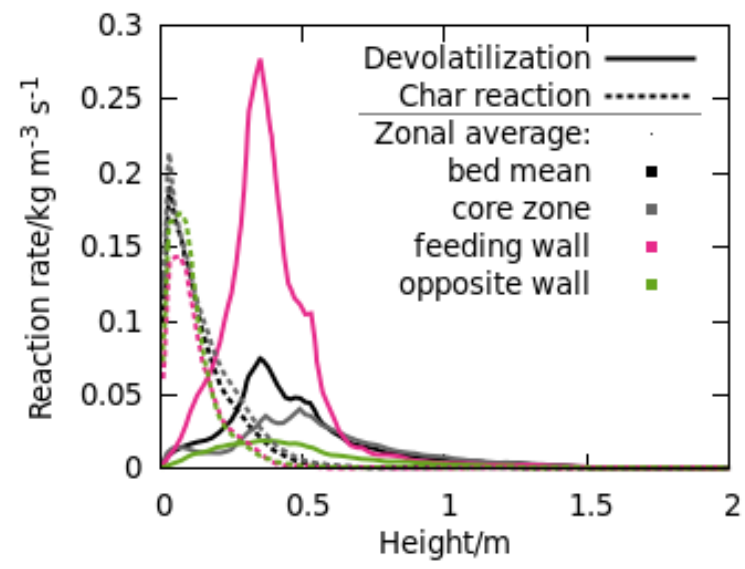

(b) Polydisperse coal

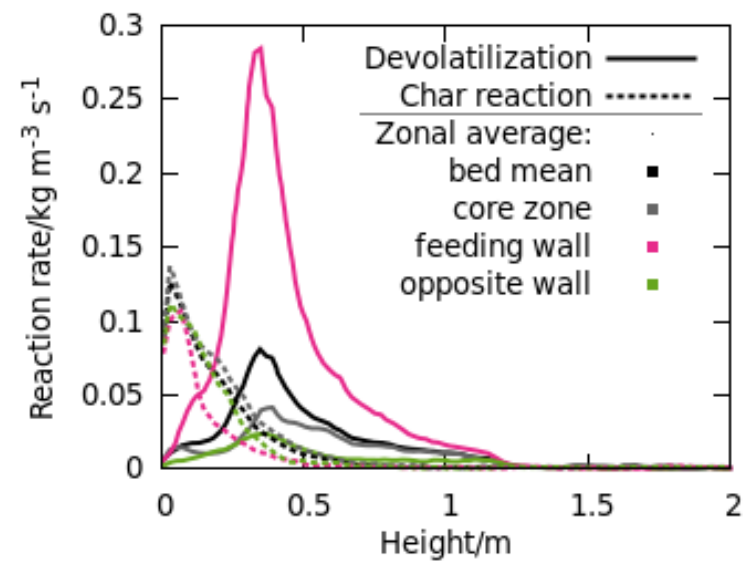

Figure 10: Vertical profiles of devolatilization and heterogeneous reaction rates, averaged by zone, for monodisperse (a) and polydisperse (b) coal particles

\section{Results: Effect of polydispersion on reaction zones}

The following two sections analyze the distribution of reaction rates and species mass fractions in the gasifier. Figures 8 and 9 (and the corresponding videos available as supplementary material) illustrate the interaction among particle dynamics, chemical reactions and production and consumption of gas species as the coal particles burn in the monodisperse and polydisperse cases. Both show the evolution with time of gas- and coal-phase volume-fractions; oxygen mass-fraction and reaction rate of its main consumption process (char oxidation); hydrogen mass fraction and reaction rates involved in its generation and consumption (devolatilization, char gasification with $\mathrm{H}_{2} \mathrm{O}$, water-gas shift reaction and hydrogen oxidation). By comparison with the mondisperse case, the polydisperse one shows a shorter bed, delayed oxygen depletion and zones with a higher hydrogen contents. The reasons for these differences will be explored in the following sections.

Figure 10 shows the vertical evolution of the zone-averaged rates of devolatilization and heterogeneous reactions for monodisperse (a) and polydisperse (b) coal. Devolatilization next to the feeding wall creates a plume of volatiles, which influences the bed hydrodynamics, and, particularly, significantly breaks the core-annulus symmetry in polydisperse cases.

Gómez-Barea and Leckner [27] addressed in a review article this lateral dispersion during devolatilization and its effect on the distribution of gaseous species. The existence of this 


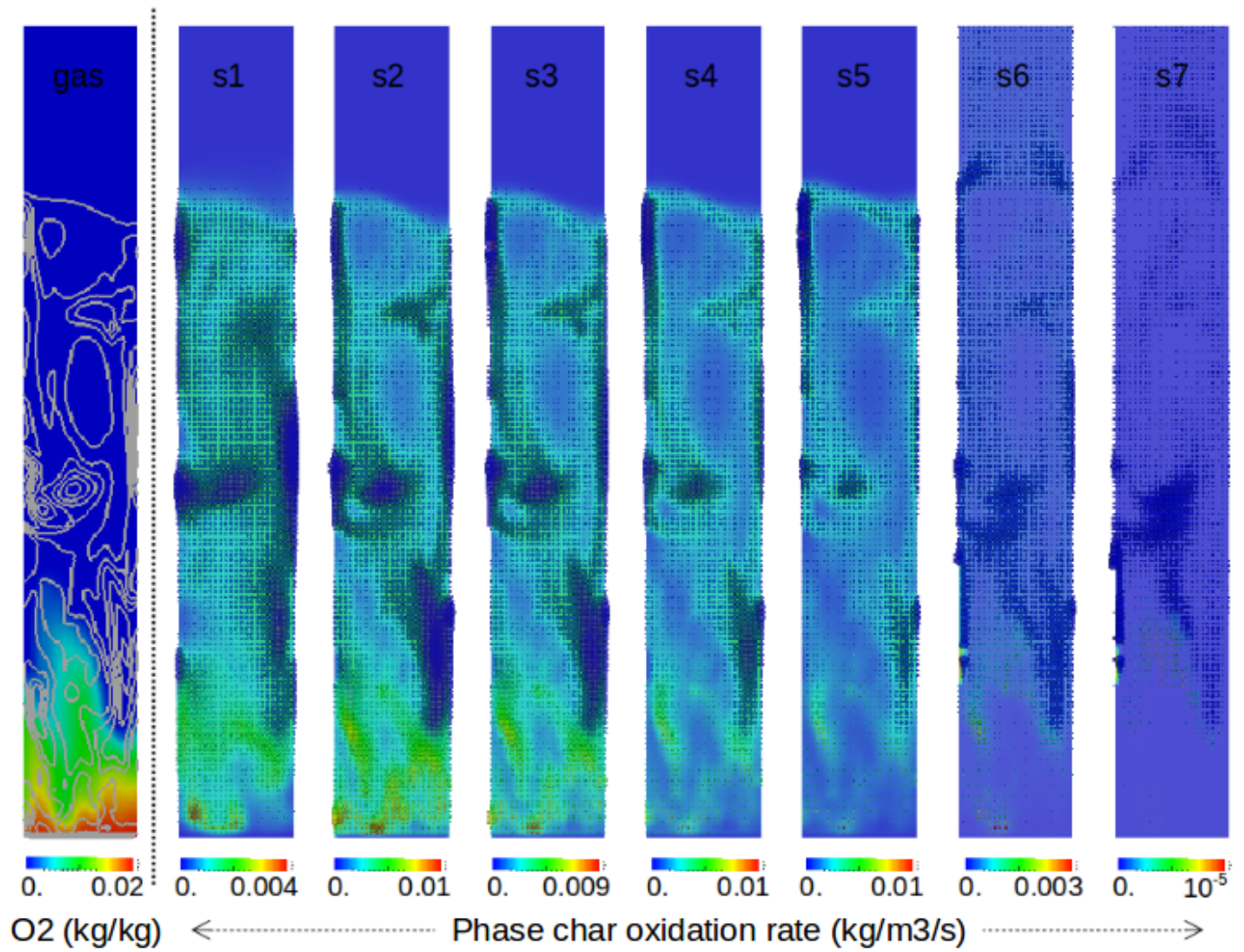

Figure 11: Polydisperse coal case. Snapshots of $\mathrm{O}_{2}$ mass-fraction contours superimposed on gas volume fraction isolines (leftmost figure), and of the solid phases, colored by the phase char-oxidation rate $\left(\mathrm{kg} / \mathrm{m}^{3} \mathrm{~s}\right)$. (The solid phases are shown as dots with a size proportional to the number density of phase particles).

volatile plume has been experimentally verified in commercial combustors. Using a simplified model (based on solving the chemical reactions in a three-dimensional bed, but imposing the vertical and horizontal velocity profiles), Petersen and Werther [46] also found plumes with large amounts of pyrolysis gas in a circulating fluidized bed gasifier for sewage sludge.

The spatial distribution of the devolatilization rates is similar for monodisperse and polydisperse coal; in both cases there is a clear asymmetry between the feeding and the opposite walls, and a peak around the injection height; however, this asymmetry persists in the upper regions of the reactor in the polydisperse case; this is probably due to the smallest particles ascending faster close to the opposite wall (as can be seen in Figure 7).

The reaction rates for char conversion (oxidation and gasification) are notably more evenly distributed than that of devolatilization, because the fluidizing gas is injected uniformly at the bed bottom. The char consumption rate is larger for the monodisperse than for the 
(a) H2 production

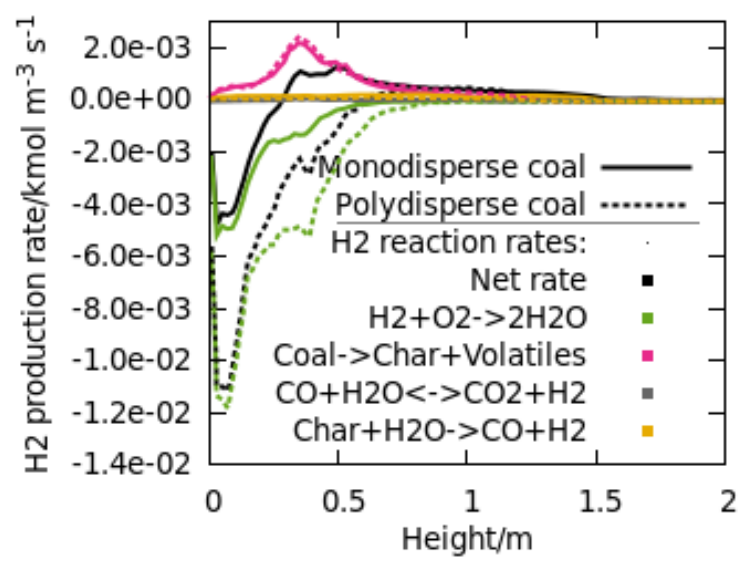

(c) $\mathrm{CH} 4$ production

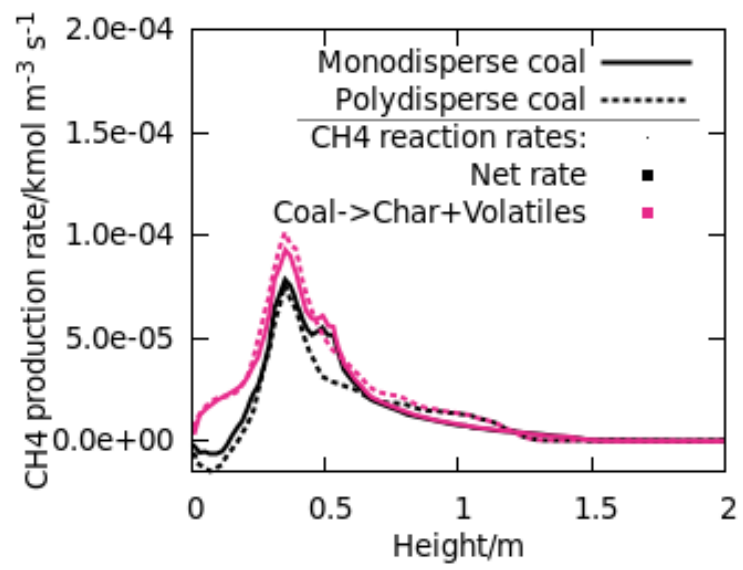

(b) CO production

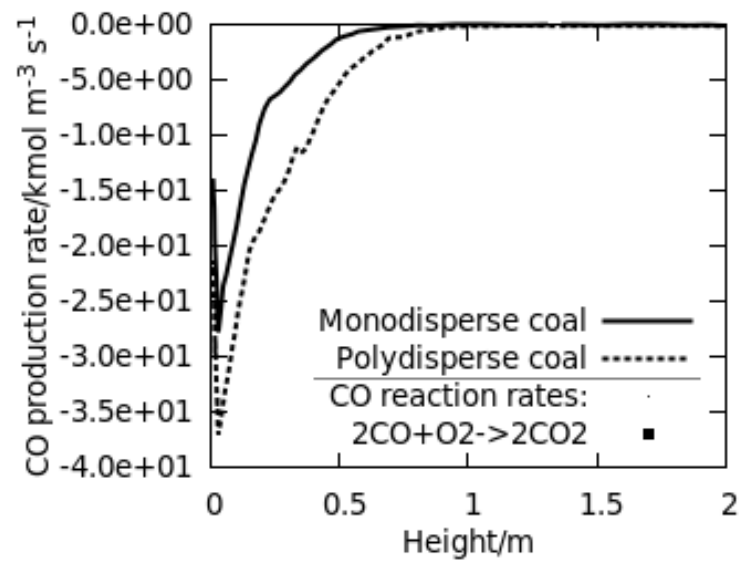

(d) O2 consumption

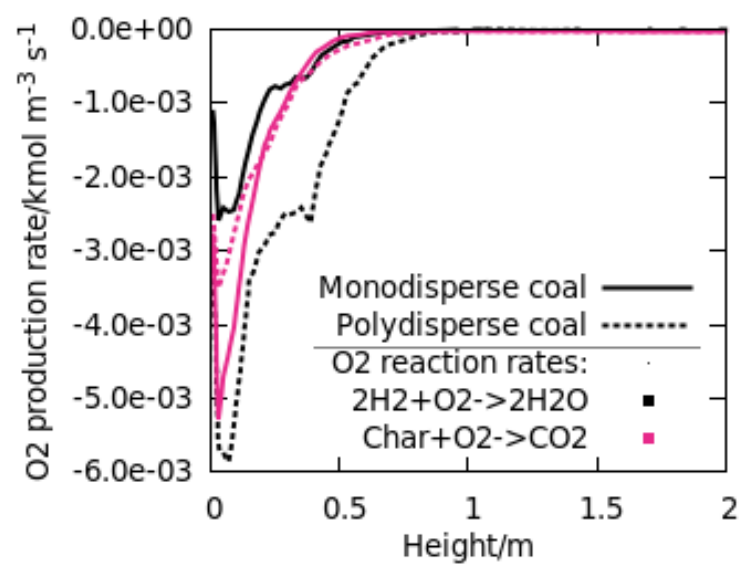

Figure 12: Vertical profile of cross-stream-averaged reaction-rates for monodisperse and polydisperse coal particles

polydisperse bed (the peak rate is greater than $35 \%$ ). This is due to the vertical segregation of coal (described in the previous section), which results in larger particles (which are less reactive) being present in the bottom layers in the polydisperse case. Figure 11 illustrates this behavior by presenting snapshots of the particle number-density for each phase (represented by scaled spheres, see description in Section 5) colored by the char oxidation rate.

The slower heterogeneous chemical kinetics in the polydisperse case in the lower part of the bed means that more oxygen is available to volatile combustion in the upper zones. This is very clearly seen in Figure 12, which shows the vertical profiles of cross-stream-averaged reaction-rates (a). 


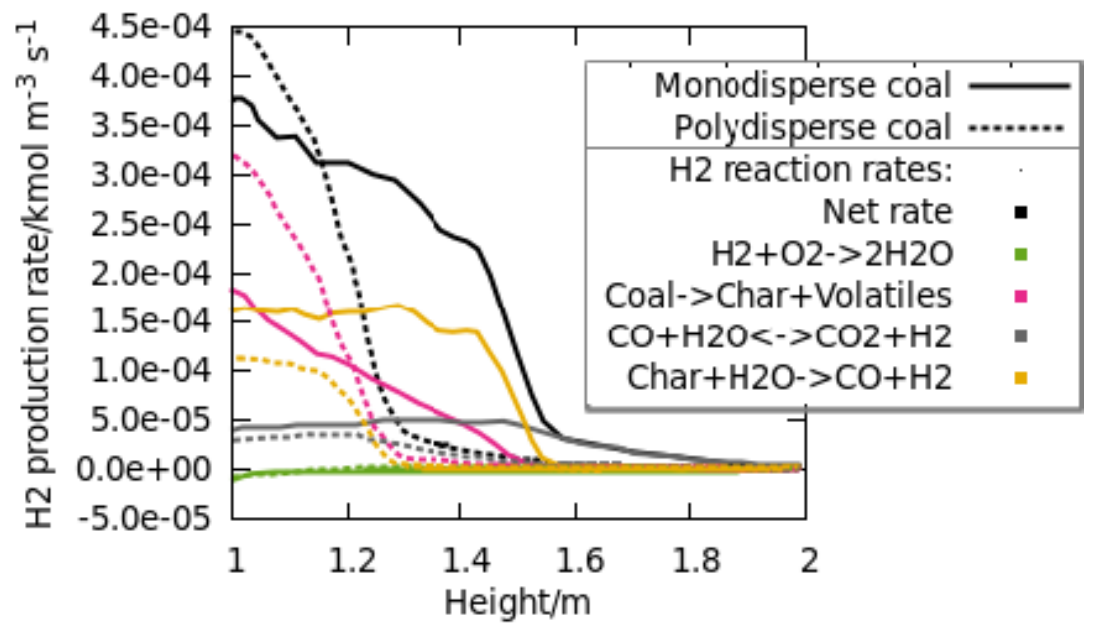

Figure 13: Vertical profile of $\mathrm{H}_{2}$ reaction rates (cross-stream-averaged) downstream of the $\mathrm{O}_{2}$ depletion point (gasification vertical zone in Figure 1) for monodisperse and polydisperse coal

The difference in heterogeneous reaction kinetics has implications for $\mathrm{H}_{2}$ levels in the bed: the competition between $\mathrm{H}_{2}$ generation by devolatilization and its consumption by oxidation differs in the monodisperse and the polydisperse case: net production of $\mathrm{H}_{2}$ starts later (further up the reactor) in the polydisperse bed because oxidation is stronger earlier due to the availability of oxygen.

Once the oxygen in the gasifier is consumed in the lower regions, the $\mathrm{H}_{2}$ kinetics in the upper regions of the gasifier are also different for monodisperse and polydisperse coal. Figure 13 presents the importance of devolatilization, char gasification by $\mathrm{H}_{2} \mathrm{O}$ and the water-gas shift reaction; a fourth reaction, $\mathrm{H}_{2}$ oxidation by $\mathrm{O}_{2}$, is shown to be negligible in this zone because $\mathrm{O}_{2}$ has been largely depleted earlier. The figure reveals that the predominant source of $\mathrm{H}_{2}$ is char gasification for monodisperse coal, while it is devolatilization for polydisperse coal. The water-gas shift reaction is in the direction of $\mathrm{H}_{2}$ production for both monodisperse and polydisperse coal; the reaction continues after the bed along the freeboard.

\section{Results: Effect of polydispersion on the spatial distribution of species}

The time-averaged mass-fraction contours of gas species presented in Figure 14 evince that the volatile plume is narrower, and the $\mathrm{O}_{2}$ depleted later, with polydisperse than with monodisperse coal. The ensuing non-uniformity in the gas density (which is lighter close to 
(a) Mondisperse coal

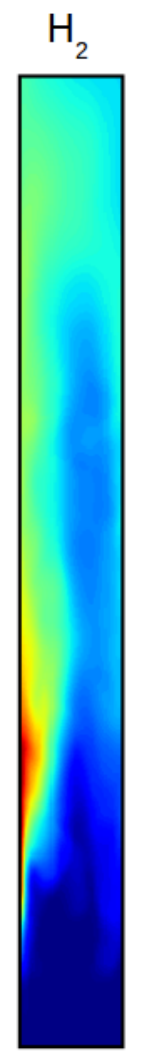

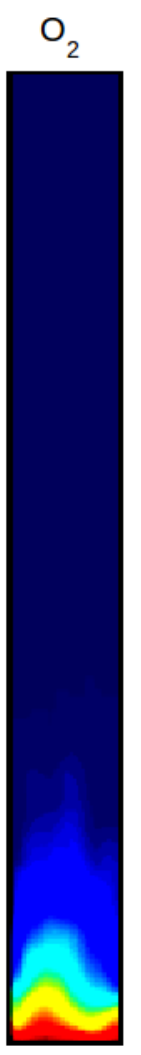

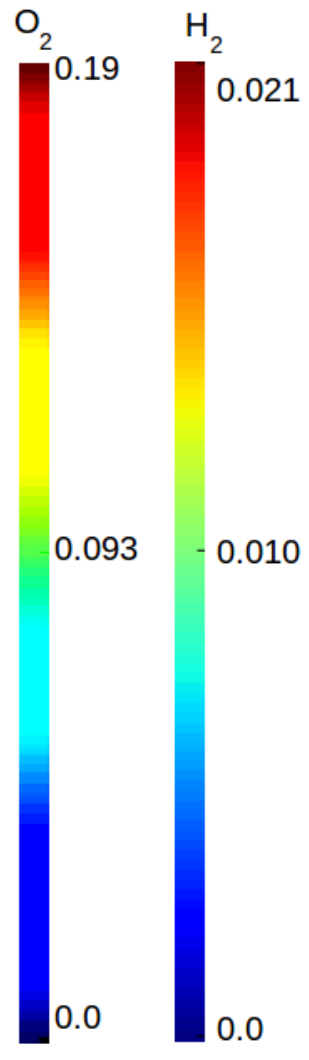

(b) Polydisperse coal

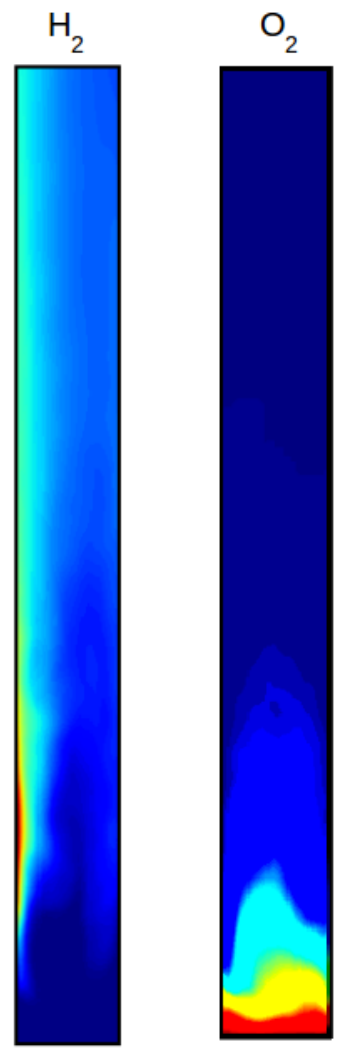

Figure 14: Contours of time-averaged $\mathrm{H}_{2}$ and $\mathrm{O}_{2}$ mass fractions for monodisperse (a) and polydisperse (b) coal 
(a) Major species for monodisperse coal particles

(b) Minor species for monodisperse coal particles
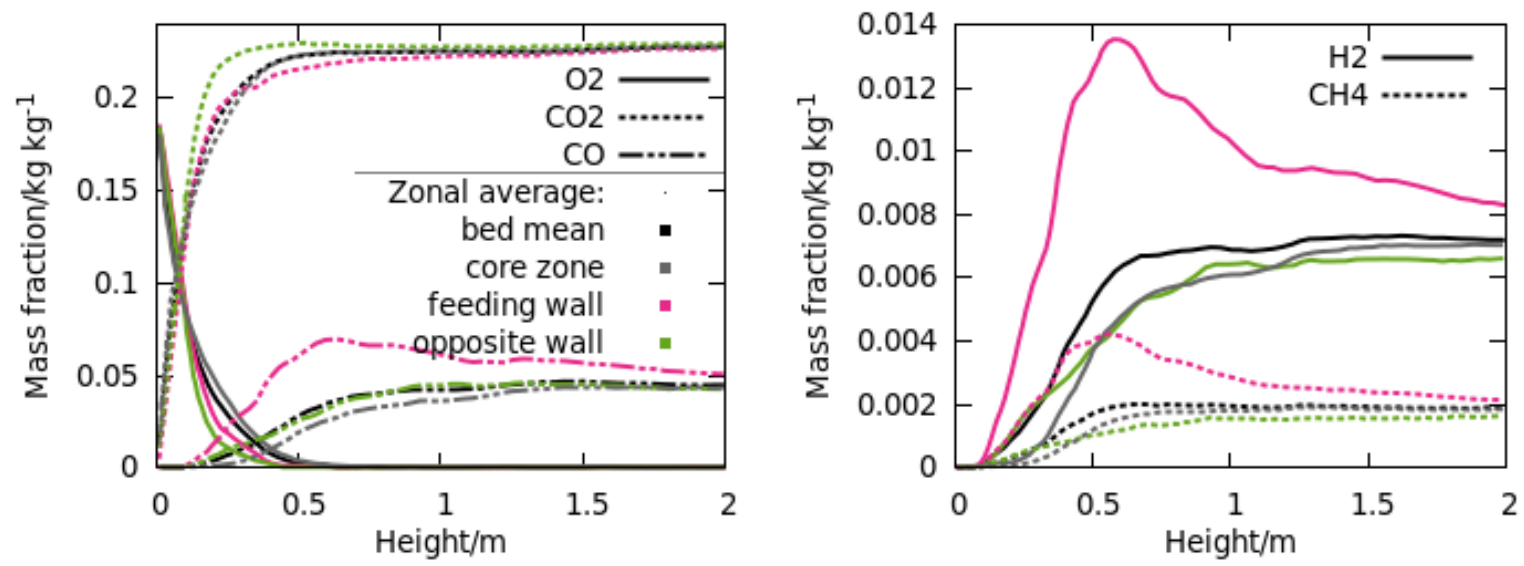

(c) Major species for polydisperse coal particles

(d) Minor species for polydisperse coal particles
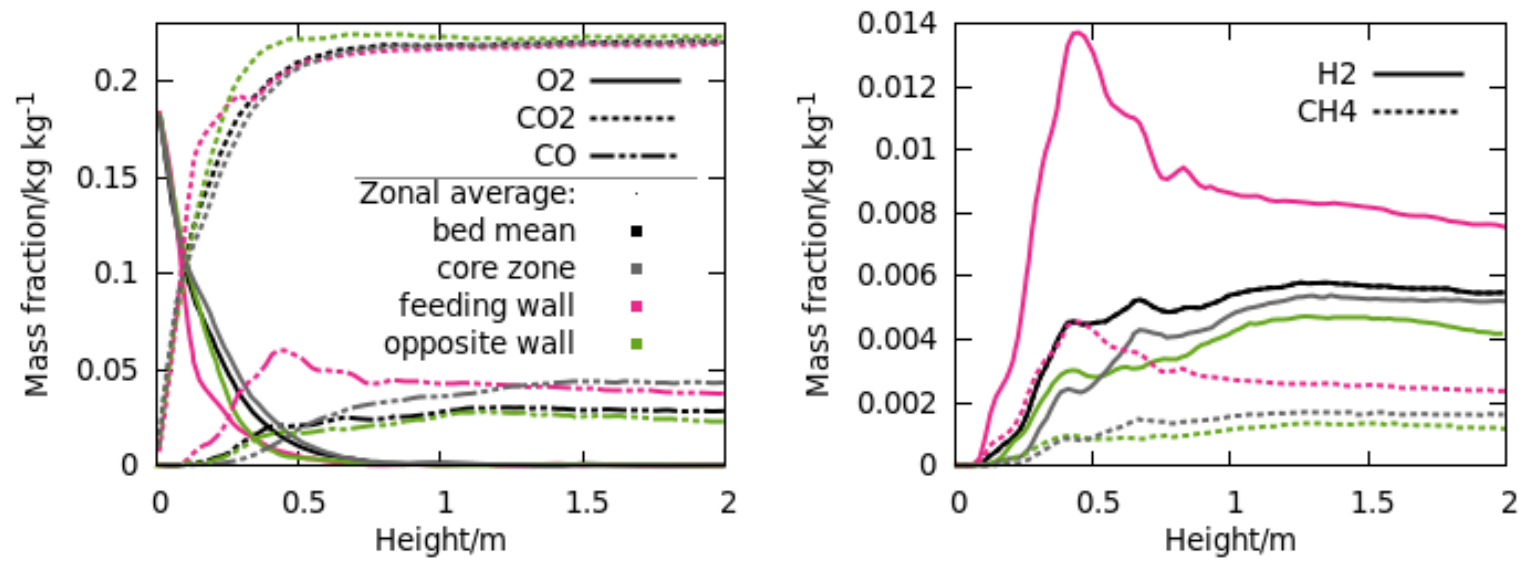

Figure 15: Evolution with height of major $(\mathrm{a}, \mathrm{c})$ and minor $(\mathrm{b}, \mathrm{d})$ species, zone averaged, for monodisperse $(\mathrm{a}, \mathrm{b})$ and polydisperse $(\mathrm{c}, \mathrm{d})$ coal particles

the feeding zone) is responsible for the strong lateral asymmetry in the flow pattern found in Section 5 .

Vertical profiles of the zone-averaged mass-fractions (Figure 15) provide a quantification of these differences. As a consequence of increased availability of oxygen with polydisperse coal, the mean mass fractions of the gasification products $\mathrm{CO}$ and $\mathrm{H}_{2}$ at the outlet are reduced by $45 \%$ and $22 \%$ respectively with respect to the monodisperse case.

Furthermore, the asymmetry in the gas composition at the reactor outlet is significantly more marked for the polysdisperse coal: the difference between the $\mathrm{H}_{2}$ mass fraction averaged across the feeding and opposite zones is about $80 \%$ with respect to the mean value; for 


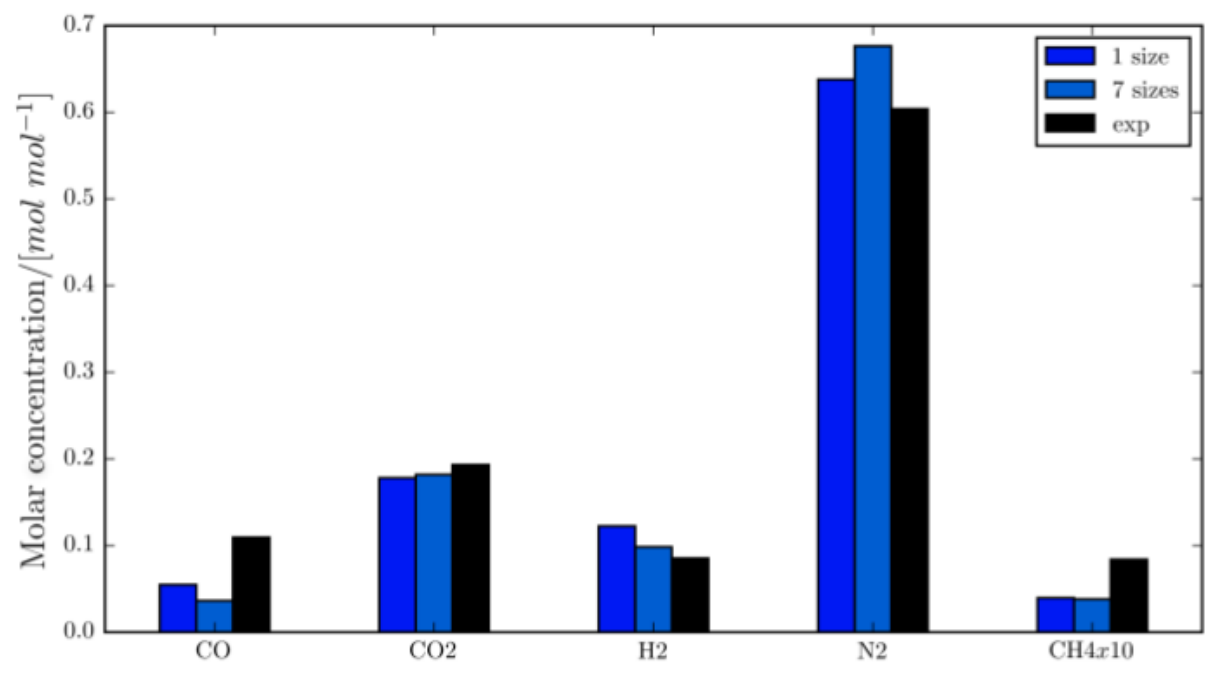

Figure 16: Comparison of predicted and experimental gas composition at the outlet

monodisperse coal, instead, it is smaller than $30 \%$. Moreover, oxygen consumption is faster at the feeding wall in the polydisperse case because of volatiles descending from the feeding point. By comparison, the bed with monodisperse coal presents a faster oxygen consumption at the opposite wall, where oxidation is predominant due to the core-annulus pattern.

Finally, the gas composition predicted at the gasifier outlet is compared with the available experimental data in Figure 16.

The agreement is reasonable. The discrepancies are the same order of magnitude as other computational results reported in literature (see, for example, $[5,51,69,76]$ ). The chemical kinetics of the reactions involved in coal gasification are not well established, and some calibration of the kinetic parameters could provide a better agreement. For example, de SouzaSantos [20] reported that taking into account the effect of poisoning substances on the kinetic parameters of the water-gas shift reaction leads to drastically reduced deviations in the concentrations of $\mathrm{H}_{2}$ and $\mathrm{CO}$ predicted with his one-dimensional model. Nevertheless, the main objective of the present article is the investigation of the influence of coal polydispersion on the gasifier performance; and the main qualitative conclusions, such as the delay in oxygen consumption by char oxidation or the uneven composition of the gas produced, would remain valid even if the kinetic parameters were optimized for a better fit of the experimental exit-gas composition. 


\section{Conclusions}

An Eulerian-Eulerian model has been developed to simulate coal gasification. It has been applied to a pilot-scale fluidized bed with the aim of providing some insight on the influence of particle polydispersion on flow patterns and species distributions within the riser, and hence, on the overall reactor performance.

A vertical segregation of coal by size is very apparent for the polydisperse-coal case. The larger particles move preferentially towards the bed bottom and the smaller ones towards the top, while the finest ones are elutriated from the bed. Interestingly, the largest particles hardly participate in the hydrodynamics of fluidization. Coal polydispersion leads to shorter beds with respect to a binary coal-limestone mixture with a single coal size. Regarding the lateral distribution, the structure known as core-annulus is well reproduced by the model for both mono- and polydisperse cases.

The main differences regarding bed dynamics between the inert and the reactive beds are the increased bed expansion and an increased transversal asymmetry in the flow pattern in the reactive flow. The transversal asymmetry is caused primarily by the volatile plume rising from the coal-injection location; this asymmetry is stronger for polydisperse than for monodisperse coal.

Polydispersion also changes the gasification dynamics. It has been shown that once the oxygen in the gasifier is consumed in the lower regions, the $\mathrm{H}_{2}$ kinetics in the upper regions of the gasifier are also different for monodisperse and polydisperse coal. In the upper zone of the reactor, the predominant source of $\mathrm{H}_{2}$ is char gasification in the case of monodisperse coal, while it is devolatilization for polydisperse coal.

Some model refinements could lead to improvements in accuracy. These refinements include: the use of detailed chemical mechanisms, and the calibration of their kinetic parameters; the modeling of particle breakup (for instance by applying an extension of the "shadow" technique); or a more systematic analysis of the influence of the particle-gas drag models.

\section{Acknowledgement}

The research presented in this paper was funded by the Spanish Ministry of Economy and Competitiveness under the INGENIO 2010 program, project CONSOLIDER CSD 2010-00011, 
and by the European Regional Development Fund (FEDER) through the Aragón Government program 'Construyendo Europa desde Aragón'.

\section{References}

[1] Cantera 2.2.1 documentation. http://www.cantera.org/.

[2] Openfoam (version 2.2.2). http://www.openfoam.org/.

[3] A. Almuttahar and F. Taghipour. Computational fluid dynamics of a circulating fluidized bed under various fluidization conditions. Chemical Engineering Science, 63(6):1696-1709, 2008.

[4] M. J. Andrews and P. J. O'Rourke. The multiphase particle-in-cell (MP-PIC) method for dense particulate flows. International Journal of Multiphase Flow, 22(2):379 - 402, 1996.

[5] L. Armstrong, S. Gu, and K. Luo. Effects of limestone calcination on the gasification processes in a BFB coal gasifier. Chemical Engineering Journal, 168(2):848 - 860, 2011.

[6] R. Beetstra, J. Nijenhuis, N. Ellis, and J. Van Ommen. The influence of the particle size distribution on fluidized bed hydrodynamics using high-throughput experimentation. AIChE Journal, 55(8):2013-2023, 2009.

[7] F. Chejne and J. P. Hernández. Modelling and simulation of coal gasification process in fluidised bed. Fuel, 81(13):1687-1702, 2002.

[8] J. Chen, W. Yin, S. Wang, G. Yu, J. Li, T. Hu, and F. Lin. Modelling of coal/biomass cogasification in internal circulating fluidized bed using kinetic theory of granular mixture. Energy Conversion and Management, 148:506-516, 2017.

[9] J. Chew, R. Hays, J. Findlay, S. Karri, T. Knowlton, R. Cocco, and C. Hrenya. Species segregation of binary mixtures and a continuous size distribution of Group B particles in riser flow. Chemical Engineering Science, 66(20):4595-4604, 2011.

[10] J. Chew and C. Hrenya. Link between bubbling and segregation patterns in gas-fluidized beds with continuous size distributions. AIChE Journal, 57(11):3003-3011, 2011. 
[11] J. Chew, D. Parker, and C. Hrenya. Elutriation and species segregation characteristics of polydisperse mixtures of Group B particles in a dilute CFB riser. AIChE Journal, 59(1):84-95, 2013.

[12] J. Chew, J. Wolz, and C. b. Hrenya. Axial segregation in bubbling gas-fluidized beds with gaussian and lognormal distributions of Geldart Group B particles. AIChE Journal, 56(12):3049-3061, 2010.

[13] M. Chiesa, V. Mathiesen, J. A. Melheim, and B. Halvorsen. Numerical simulation of particulate flow by the Eulerian-Lagrangian and the Eulerian-Eulerian approach with application to a fluidized bed. Computers and Chemical Engineering, 29(2):291 - 304, 2005 .

[14] C. T. Crowe, M. P. Sharma, and D. E. Stock. The Particle-Source-In Cell (PSI-CELL) Model for Gas-Droplet Flows. ASME. J. Fluids Eng., 99(2):325-332, 1977.

[15] A. Cubero, A. Sánchez-Insa, and N. Fueyo. A consistent momentum interpolation method for steady and unsteady multiphase flows. Computers and Chemical Engineering, 62:96$107,2014$.

[16] A. Cubero, A. Sánchez-Insa, and N. Fueyo. Crossing trajectories and phase change in Eulerian-Eulerian models of disperse multiphase flows. International Journal of Multiphase Flow, 72:141 - 144, 2015.

[17] P. A. Cundall and O. D. L. Strack. Discrete numerical-model for granular assemblies. Geotechnique, 29:47-65, 1979.

[18] S. Dahl and C. Hrenya. Size segregation in gas-solid fluidized beds with continuous size distributions. Chemical Engineering Science, 60(23):6658-6673, 2005.

[19] M. L. de Souza-Santos. Modelling and simulation of fluidized-bed boilers and gasifiers for carbonaceous solids. PhD thesis, University of Sheffield, 1987.

[20] M. L. de Souza-Santos. Comprehensive simulator applied to fluidized bed coal gasification. The Open Chemical Engineering Journal, 4:68 - 79, 2010. 
[21] R. Fan and R. Fox. Segregation in polydisperse fluidized beds: Validation of a multi-fluid model. Chemical Engineering Science, 63(1):272-285, 2008.

[22] N. Fueyo, J. Ballester, and C. Dopazo. The computation of particle size in Eulerian/Eulerian models of coal combustion. International Journal of Multiphase Flow, pages 607-612, 1997.

[23] D. Gera, M. Syamlal, and T. O'Brien. Hydrodynamics of particle segregation in fluidized beds. International Journal of Multiphase Flow, 30(4):419-428, 2004.

[24] S. Gerber, F. Behrendt, and M. Oevermann. An Eulerian modeling approach of wood gasification in a bubbling fluidized bed reactor using char as bed material. Fuel, 89(10):2903 $-2917,2010$.

[25] D. Gidaspow. Multiphase Flow and Fluidization. Academic Press, Boston, 1996.

[26] M. Goldschmidt, J. Kuipers, and W. Van Swaaij. Hydrodynamic modelling of dense gasfluidised beds using the kinetic theory of granular flow: Effect of coefficient of restitution on bed dynamics. Chemical Engineering Science, 56(2):571-578, 2001.

[27] A. Gómez-Barea and B. Leckner. Modeling of biomass gasification in fluidized bed. Progress in Energy and Combustion Science, 36(4):444-509, 2010.

[28] J. Grace and G. Sun. Influence of particle size distribution on the performance of fluidized bed reactors. Canadian Journal of Chemical Engineering, 69(5):1126-1134, 1991.

[29] D. Gunn. Transfer of heat or mass to particles in fixed and fluidised beds. International Journal of Heat and Mass Transfer, 21(4):467-476, 1978.

[30] F. H. Harlow. A machine calculation method for hydrodynamic problems. In Los Alamos Scientific Laboratory report LAMS-1956, Nov 1955.

[31] S.-S. Hsiau. Effective thermal conductivities of a single species and a binary mixture of granular materials. International Journal of Multiphase Flow, 26(1):83-97, 2000.

[32] C. Ibsen, E. Helland, B. Hjertager, T. Solberg, L. Tadrist, and R. Occelli. Comparison of multifluid and discrete particle modelling in numerical predictions of gas particle flow in circulating fluidised beds. Powder Technology, 149(1):29 - 41, 2004. 
[33] T. Ismail, M. Abd El-Salam, E. Monteiro, and A. Rouboa. Eulerian-Eulerian CFD model on fluidized bed gasifier using coffee husks as fuel. Applied Thermal Engineering, 106:1391$1402,2016$.

[34] G. Joseph, J. Leboreiro, C. Hrenya, and A. Stevens. Experimental segregation profiles in bubbling gas-fluidized beds. AIChE Journal, 53(11):2804-2813, 2007.

[35] H. Kobayashi, J. Howard, and A. Sarofim. Coal devolatilization at high temperatures. Symposium (International) on Combustion, The Combustion Institute, 16(1):411-425, 1977.

[36] X. Ku, T. Li, and T. Lvs. CFD-DEM simulation of biomass gasification with steam in a fluidized bed reactor. Chemical Engineering Science, 122:270-283, 2015.

[37] C.-L. Lin, M.-Y. Wey, and S.-D. You. The effect of particle size distribution on minimum fluidization velocity at high temperature. Powder Technology, 126(3):297-301, 2002.

[38] B. Liu, K. Papadikis, S. Gu, B. Fidalgo, P. Longhurst, Z. Li, and A. Kolios. CFD modelling of particle shrinkage in a fluidized bed for biomass fast pyrolysis with quadrature method of moment. Fuel Processing Technology, 164:51-68, 2017.

[39] R. Loison and R. Chauvin. Pyrolyse rapide du carbon. Chemie et Industrie, 91:269, 1964.

[40] V. Mathiesen, T. Solberg, and B. Hjertager. An experimental and computational study of multiphase flow behavior in a circulating fluidized bed. International Journal of Multiphase Flow, 26(3):387-419, 2000.

[41] V. Mathiesen, T. Solberg, and B. H. Hjertager. Predictions of gas/particle flow with an Eulerian model including a realistic particle size distribution. Powder Technology, 112(1-2):34-45, 2000.

[42] J. Musser, M. Syamlal, M. Shahnam, and D. Huckaby. Constitutive equation for heat transfer caused by mass transfer. Chemical Engineering Science, 123:436-443, 2015.

[43] A. Nikolopoulos, I. Malgarinos, N. Nikolopoulos, P. Grammelis, S. Karrelas, and E. Kakaras. A decoupled approach for nox-n2o 3-d cfd modeling in cfb plants. Fuel, 115:401-415, 2014. 
[44] A. Ocampo, E. Arenas, F. Chejne, J. Espinel, C. Londoo, J. Aguirre, and J. D. Perez. An experimental study on gasification of Colombian coal in fluidised bed. Fuel, 82(2):161-164, 2003.

[45] A. Passalacqua, R. Fox, R. Garg, and S. Subramaniam. A fully coupled quadrature-based moment method for dilute to moderately dilute fluid-particle flows. Chemical Engineering Science, 65(7):2267-2283, 2010.

[46] I. Petersen and J. Werther. Three-dimensional modeling of a circulating fluidized bed gasifier for sewage sludge. Chemical Engineering Science, 60(16):4469-4484, 2005.

[47] H. Qi, F. Li, B. Xi, and C. You. Modeling of drag with the Eulerian approach and EMMS theory for heterogeneous dense gas-solid two-phase flow. Chemical Engineering Science, 62(6):1670-1681, 2007.

[48] Z. Qin, Q. Zhou, and J. Wang. An EMMS drag model for coarse grid simulation of polydisperse gassolid flow in circulating fluidized bed risers. Chemical Engineering Science, $207: 358-378,2019$.

[49] A. Ramos, E. Monteiro, and A. Rouboa. Numerical approaches and comprehensive models for gasification process: A review. Renewable and Sustainable Energy Reviews, 110:188$206,2019$.

[50] A. Sánchez-Insa. Un algoritmo consistente para la simulacin de flujos multifsicos reactivos, y su aplicacin a lechos fluidos. PhD thesis, University of Zaragoza, October 2015.

[51] W. Shuai, L. Huang, H. Zhenhua, L. Huilin, L. Guodong, L. Dan, and Z. Feixiang. Numerical modeling of a bubbling fluidized bed coal gasifier by kinetic theory of rough spheres. Fuel, 130:197-202, 2014.

[52] W. Shuai, C. Juhui, L. Guodong, L. Huilin, Z. Feixiang, and Z. Yanan. Predictions of coal combustion and desulfurization in a CFB riser reactor by kinetic theory of granular mixture with unequal granular temperature. Fuel Processing Technology, 126:163-172, 2014. 
[53] L. Silva, R. Rodrigues, J. Mitre, and P. Lage. Comparison of the accuracy and performance of quadrature-based methods for population balance problems with simultaneous breakage and aggregation. Computers and Chemical Engineering, 34(3):286-297, 2010.

[54] R. I. Singh, A. Brink, and M. Hupa. CFD modeling to study fluidized bed combustion and gasification. Applied Thermal Engineering, 52(2):585 - 614, 2013.

[55] D. M. Snider. An incompressible three-dimensional multiphase particle-in-cell model for dense particle flows. Journal of Computational Physics, 170(2):523-549, 2001.

[56] D. M. Snider, S. M. Clark, and P. J. O‘Rourke. Eulerian-Lagrangian method for threedimensional thermal reacting flow with application to coal gasifiers. Chemical Engineering Science, 66(6):1285-1295, 2011.

[57] D. M. Snider, P. J. O‘Rourke, and M. J. Andrews. An Incompressible Two-Dimensional Multiphase Particle-in-Cell Model for Dense Particle Flows, NM, LA-13280-MS. In Los Alamos National Laboratories, Los Alamos, NM, 1997.

[58] D. Spalding. The SHADOW method of particle-size calculation in two-phase combustion. 19th Symposium (International) on Combustion, The Combustion Institute, pages 941951.

[59] A. Stroh, F. Alobaid, M. von Bohnstein, J. Ströhle, and B. Epple. Numerical CFD simulation of 1 MWth circulating fluidized bed using the coarse grain discrete element method with homogenous drag models and particle size distribution. Fuel Processing Technology, 169:84-93, 2018.

[60] G. Sun. Influence of particle size distribution on the performance of fluidized bed reactors. PhD thesis, The University of British Columbia, Vancouver, Canada, 1991.

[61] M. Syamlal. The particle-particle drag term in a multiparticle model of fluidization. In DOE/MC/21353-2373, NTIS/DE87006500, National Technical Information Service, Springfield, VA, 1987.

[62] M. Syamlal and D. Gidaspow. Hydrodynamics of fluidization: Prediction of wall to bed heat transfer coefficients. AICHE J, 31:127-135, 1985. 
[63] M. Syamlal and T. O'Brien. The derivation of a drag coefficient formula from velocityvoidage correlations. In Unpublished report, April 1987.

[64] Y. Tsuji, T. Kawaguchi, and T. Tanaka. Discrete particle simulation of two-dimensional fluidized bed. Powder Technology, 77(1):79 - 87, 1993.

[65] M. van Sint Annaland, G. Bokkers, M. Goldschmidt, M. van der Hoef, and J. Kuipers. Development of a multi-fluid model for poly-disperse dense gas-solid fluidised beds, part ii: Segregation in binary particle mixtures. Chemical Engineering Science, 64(20):4237-4246, 2009 .

[66] B. G. M. van Wachem, J. C. Schouten, C. M. van den Bleek, R. Krishna, and J. L. Sinclair. CFD modeling of gas-fluidized beds with a bimodal particle mixture. AIChE Journal, 47(6):1292-1302, 2001.

[67] C. Wang and J. Zhu. Developments in the understanding of gas-solid contact efficiency in the circulating fluidized bed riser reactor: A review. Chinese Journal of Chemical Engineering, 24(1):53-62, 2016.

[68] S. Wang, K. Zhang, S. Xu, and X. Yang. Assessment of a bubble-based bi-disperse drag model for the simulation of a bubbling fluidized bed with a binary mixture. Powder Technology, 338:280-288, 2018.

[69] X. Wang, B. Jin, and W. Zhong. Three-dimensional simulation of fluidized bed coal gasification. Chemical Engineering and Processing: Process Intensification, 48(2):695$705,2009$.

[70] H. G. Weller, G. Tabor, H. Jasak, and C. Fureby. A tensorial approach to computational continuum mechanics using object-oriented techniques. Computers in Physics, 12(6):620$631,1998$.

[71] J. Xie, W. Zhong, B. Jin, Y. Shao, and Y. Huang. Eulerian-Lagrangian method for threedimensional simulation of fluidized bed coal gasification. Advanced Powder Technology, 24(1):382-392, 2013. 
[72] J. Xie, W. Zhong, B. Jin, Y. Shao, and H. Liu. Three-dimensional eulerian-eulerian modeling of gaseous pollutant emissions from circulating fluidized-bed combustors. Energy and Fuels, 28(8):5523-5533, 2014.

[73] Q. Xiong, S.-C. Kong, and A. Passalacqua. Development of a generalized numerical framework for simulating biomass fast pyrolysis in fluidized-bed reactors. Chemical Engineering Science, 99:305 - 313, 2013.

[74] Q. Xue and R. Fox. Multi-fluid CFD modeling of biomass gasification in polydisperse fluidized-bed gasifiers. Powder Technology, 254:187-198, 2014.

[75] Q. Xue and R. Fox. Computational modeling of biomass thermochemical conversion in fluidized beds: Particle density variation and size distribution. Industrial and Engineering Chemistry Research, 54(16):4084-4094, 2015.

[76] L. Yu, J. Lu, X. Zhang, S. Zhang, and X. Wang. Two fluid model using kinetic theory for modeling of one-step hydrogen production gasifier. AIChE Journal, 11:2833-2851, 2008.

[77] M. Zeneli, A. Nikolopoulos, N. Nikolopoulos, P. Grammelis, S. Karellas, and E. Kakaras. Simulation of the reacting flow within a pilot scale calciner by means of a three phase tfm model. Fuel Processing Technology, 162:105-125, 2017.

[78] Y. Zhang, B. Jin, and W. Zhong. Experimental investigation on mixing and segregation behavior of biomass particle in fluidized bed. Chemical Engineering and Processing: Process Intensification, 48(3):745-754, 2009.

[79] W. Zhong, A. Yu, G. Zhou, J. Xie, and H. Zhang. CFD simulation of dense particulate reaction system: Approaches, recent advances and applications. Chemical Engineering Science, 140:16-43, 2016.

[80] Q. Zhou and J. Wang. CFD study of mixing and segregation in CFB risers: Extension of EMMS drag model to binary gas-solid flow. Chemical Engineering Science, 122:637-651, 2015.

[81] W. Zhou, C. Zhao, L. Duan, X. Chen, and C. Liang. Two-dimensional computational fluid dynamics simulation of nitrogen and sulfur oxides emissions in a circulating fluidized bed combustor. Chemical Engineering Journal, 173(2):564-573, 2011. 
760

761

762

763

$764 \quad \bar{I}$ Identity matrix

$765 \gamma_{s}$ Collisional dissipation

$766 \quad \kappa_{s}^{\Theta}$ Granular temperature conductivity

${ }_{767} \mu_{s}^{\text {dil }}$ Dilute dynamic viscosity

${ }_{768} \overline{\Theta_{s}}$ Average granular temperature

${ }_{769} \sum_{q(s)}$ Sum over all the solid phases

$770 \quad \xi_{s}$ Bulk viscosity

$771 \quad d_{s}$ Particle diameter

$772 e_{s}$ Particle restitution coefficient

$773 \quad g_{s z}$ Binary radial distribution

$774 l_{s}$ Mean free path

$775 \quad m_{s}$ Particle mass $\left(=\pi d_{s}^{3} \rho_{s} / 6\right)$

$776 n_{s}$ Particle number density $\left(=6 r_{s} / \pi / d_{s}^{3}\right)$

${ }_{777} p_{s z}^{c o l}$ Collision pressure between solid phases $s$ and $z$ 
$778 r_{g}^{\text {Min }}$ Minimum volume fraction of gas phase

$779 \quad s, z$ Solid phases

${ }_{780} C_{D s g}$ Solid-gas drag coefficient

${ }_{781} V_{r s g}$ Solid phase terminal velocity in gas phase

782

783 The constitutive laws for a solid phase $s$ are presented next.

$$
\begin{aligned}
& \overrightarrow{\vec{\tau}_{s}}=-p_{s} \overrightarrow{\vec{I}}+\mu_{s}\left(\nabla \vec{v}_{s}+\left(\nabla \vec{v}_{s}\right)^{T}\right)+\left(\xi_{s}-\frac{2}{3} \mu_{s}\right) \nabla \cdot \vec{v}_{s} \overrightarrow{\vec{I}} \quad ; \\
& p_{s}=r_{s} \rho_{s} \Theta_{s}+\sum_{q(s)} p_{s z}^{c o l} \quad ; \\
& p_{s z}^{c o l}=\frac{\pi}{3} d_{s z}^{3} g_{s z}\left(1+e_{s z}\right) n_{s} n_{z} m_{s} m_{z} \\
& \left(\frac{m_{s z} \Theta_{s} \Theta_{z}}{\left(m_{s}^{2} \Theta_{s}+m_{z}^{2} \Theta_{z}\right)}\right)\left(\frac{m_{s z}^{2} \Theta_{z}}{\left(m_{s}^{2} \Theta_{s}+m_{z}^{2} \Theta_{z}\right)} \frac{\Theta_{s}}{\left(\Theta_{s}+\Theta_{z}\right)}\right)^{3 / 2} \text {; } \\
& g_{s z}=g_{0}=\left[1-\left(\frac{r_{g}}{r_{g}^{M i n}}\right)^{\frac{1}{3}}\right]^{-1} \quad ; \\
& d_{s z}=\frac{1}{2}\left(d_{s}+d_{z}\right) \quad ; \quad m_{s z}=\frac{1}{2}\left(m_{s}+m_{z}\right) \quad ; \quad e_{s z}=\frac{1}{2}\left(e_{s}+e_{z}\right) \quad ; \\
& e_{s}=0.9 \quad \text { and } \quad r_{g}^{\text {Min }}=0.34 \quad \text { in this work } \quad ; \\
& \xi_{s}=\sum_{q(s)} p_{s z}^{c o l} \frac{d_{s z}}{3}\left(m_{s} \Theta_{s}+m_{z} \Theta_{z}\right) \sqrt{\frac{2}{\pi \Theta_{s} \Theta_{z}\left(m_{s}^{2} \Theta_{s}+m_{z}^{2} \Theta_{z}\right)}} ; \\
& \mu_{s}=\sum_{q(s)} p_{s z}^{c o l} \frac{d_{s z}}{5}\left(m_{s} \Theta_{s}+m_{z} \Theta_{z}\right) \sqrt{\frac{2}{\pi \Theta_{s} \Theta_{z}\left(m_{s}^{2} \Theta_{s}+m_{z}^{2} \Theta_{z}\right)}}+ \\
& +\frac{2 \mu_{s}^{d i l}}{\frac{1}{N_{s}} \sum_{q(s)}\left(1+e_{s z}\right) g_{s z}}\left(1+\frac{4}{5} \sum_{q(s)} r_{s}\left(1+e_{s z}\right) g_{s z}\right)^{2} \quad ;
\end{aligned}
$$




$$
\begin{gathered}
\mu_{s}^{d i l}=\frac{15}{8 d_{s z}^{3}} r_{s} l_{s} \sqrt{\frac{2 m_{s} \overline{\Theta_{p}}}{\pi}} ; l_{s}=\frac{1}{6 \sqrt{2}} \frac{d_{s}}{r_{s}}<l_{\text {characteristic }} \approx \Delta x \\
\frac{\overline{\Theta_{s}}}{2 m_{s} \Theta_{s}}=\left(\sum_{q(s)} \frac{n_{s}}{n_{z}} \frac{d_{s z}^{2}}{d_{q}^{2}}\left(\frac{m_{s z}^{2} \Theta_{s}}{\left(m_{s}^{2} \Theta_{s}+m_{z}^{2} \Theta_{z}\right)}\right)^{2}\left(\frac{\Theta_{z}}{\left(\Theta_{s}+\Theta_{z}\right)}\right)^{3 / 2}\right)^{-2} \\
\kappa_{s}^{\Theta}=\frac{1}{\frac{1}{N_{s}} \sum_{q(s)}\left(1+e_{s z}\right) g_{s z}}\left(1+\frac{6}{5} \sum_{q(s)}\left(1+e_{s z}\right) g_{s z} r_{z}\right)^{2}+ \\
+2 r_{s} \rho_{s} d_{s} \sqrt{\frac{\Theta_{s}}{\pi}} \sum_{q(s)}\left(1+e_{s z}\right) g_{s z} r_{z} ; \quad \kappa_{s}^{d i l}=\frac{225}{32} r_{s} l_{s} \sqrt{\frac{2 m_{s} \Theta_{p}}{\pi}} \\
\gamma_{s}=\sum_{q(s)} \frac{3}{4} p_{s z}^{c o l}\left(1-e_{s z}\right)\left[\frac{4}{d_{s z}} \sqrt{\frac{2 m_{s z}^{2} \Theta_{s} \Theta_{z}}{\pi\left(m_{s}^{2} \Theta_{s}+m_{z}^{2} \Theta_{z}\right)}}-m_{s z} \frac{m_{s} \Theta_{s}+m_{z} \Theta_{z}}{m_{s}^{2} \Theta_{s}+m_{z}^{2} \Theta_{z}} \nabla \vec{v}_{s}\right]
\end{gathered}
$$

784

785$$
\text { The drag-force coefficient between two solid phases } s \text { and } z \text { is modeled as: }
$$$$
f_{s z}^{\vec{v}}=\frac{3}{4} \frac{\rho_{s} \rho_{z}\left(d_{s}+d_{z}\right)^{2}}{\left(\rho_{s} d_{s}^{3}+\rho_{z} d_{z}^{3}\right)} g_{s z}\left(1+e_{s z}\right)\left|\vec{v}_{s}-\vec{v}_{z}\right|
$$

The interfacial interactions between a gas $(g)$ and a solid phase $(s)$ are modeled as:

$$
\begin{gathered}
f_{s g}^{\vec{v}}=\frac{3}{4 d_{s}} \rho_{g} \mathrm{C}_{\mathrm{D} s g} \frac{R e_{s g}}{V_{r_{s g}}^{3}\left|\vec{v}_{g}-\vec{v}_{s}\right|} ; \quad f_{g s}^{h}=6 k_{g} \mathrm{Nu}_{s g} / d_{s}^{2} \quad ; \\
C_{D s g}^{1 / 2}=0.63+4.8 \sqrt{V_{r_{s g}} / \operatorname{Re}_{s g}} ; V_{r_{s g}}=0.5\left(-A+\sqrt{A^{2}+0.24 B \mathrm{Re}_{s g}}\right) \\
A=0.06 \operatorname{Re}_{s g}-r_{g}^{4.14} ; B=\left\{\begin{array}{ll}
0.8 r_{g}^{1.28} & r_{g}<0.85 \\
r_{g}^{2.65} & r_{g} \geq 0.85
\end{array} ;\right. \\
\operatorname{Re}_{s g}=\frac{\rho_{s} d_{s}\left|\vec{u}_{s}-\vec{u}_{g}\right|}{\mu_{g}} \quad ; \quad \operatorname{Pr}_{g}=C_{s g} \mu_{g} / k_{g} ;
\end{gathered}
$$$$
\mathrm{Nu}_{s g}=\left(7-10 r_{g}+5 r_{g}^{2}\right)\left(1+0.7 \operatorname{Re}_{s g}^{0.2} \operatorname{Pr}_{g}^{1 / 3}\right)+\left(1.33-2.4 r_{g}+1.2 r_{g}^{2}\right) \operatorname{Re}_{s g}^{0.7} \operatorname{Pr}_{g}^{1 / 3}
$$

\section{Appendix B. Discretization of the total mass conservation equation}


789

790

791

$792 \quad A_{f}$ Area normal to cell face $f$

793

794

795

796

$797 \Delta t$ Time step size

$798 \hat{u}$ Pseudo-velocity component $(=H / a)$

$799 \quad \psi$ Adiabatic compressibility

${ }_{800} \quad \rho_{p}^{0}$ Phase reference density

${ }_{801} a^{D}$ contribution to main diagonal coefficients of drag force $\left(=f_{q p}^{\vec{v}} V\right)$

${ }_{802} a^{T}$ contribution to main diagonal coefficients of temporal term $(=\rho V / \Delta t)$

803 a Contributions to main diagonal coefficients of convective and diffusive fluxes

${ }_{804} c$ A generic cell and its center

${ }_{805} f$ A generic cell face for cell $c$

$806 \quad k$ Previous iteration

$807 \quad n$ Previous time step 
The consistent momentum interpolation technique for unsteady multiphase flows (CMI)

proposed by the authors has been extended in this work to manage variable phase density and interphase mass transfer [15]. The total-mass conservation-equation (obtained by summing the mass-conservation equations for the volume fraction for all the phases) is discretized as follows:

$$
\begin{aligned}
& -\sum_{f} A_{f} \sum_{p}\left\lfloor\frac{\rho_{p}}{\rho_{p}^{0}}\right\rfloor_{f} \frac{1}{1+\left\{a_{p}^{T} / a_{p}\right\}_{f}+\left\{a_{p}^{D} / a_{p}\right\}_{f}}\left\lfloor r_{p}\right\rfloor_{f}\left\lfloor\frac{1}{a_{p}}\right\rfloor_{f}\{G\}_{f}^{k+1} \\
& =\sum_{f} A_{f} \sum_{p}\left\lfloor\frac{\rho_{p}}{\rho_{p}^{0}}\right\rfloor_{f} \frac{1}{1+\left\{a_{p}^{T} / a_{p}\right\}_{f}+\left\{a_{p}^{D} / a_{p}\right\}_{f}}\left\{\lfloor\widehat{u}\rfloor_{f}+\left\{a_{p}^{T} / a_{p}\right\}_{f}^{n}\left\{u_{p}^{\mathrm{CMI}}\right\}_{f}^{n}+\left\{a_{p}^{D} / a_{p}\right\}_{f}\left\{u_{p}^{\mathrm{CMI}}\right\}_{f}\right\} \\
& +\frac{V_{c}}{\rho_{g}^{0} \Delta t}\left\{\left\{\psi_{g} r_{g} p\right\}_{c}-\left\{\psi_{g} r_{g} p\right\}_{c}^{n}\right\}+\sum_{q(s)} \frac{V_{c}}{\rho_{q}^{0} \Delta t}\left\{\left\{\rho_{q} r_{q}\right\}_{c}-\left\{\rho_{q} r_{q}\right\}_{c}^{n}\right\} \\
& -\sum_{p} \frac{1}{\rho_{p}^{0}} \sum_{x} \sum_{q} \dot{m}_{q p}^{x} .
\end{aligned}
$$

This is the equation for pressure $p$, with $G$ representing the pressure gradient (which involves in the momentum interpolation equations); as it is usually done for gas flows with variable density, the gas density is expressed as a function of the adiabatic compressibility $\left(\rho_{g}=\psi p\right)$ and then the pressure appears as an unknown in the second term on the RHS. The last term includes the interphase mass transfer rate, and is due to the use of a phase reference density $\left(\rho_{s}^{0}\right)$. This reference density is introduced in order to avoid too large differences between the contribution for the different phases. The rest of nomenclature is the same as in the original paper [15], except that there $\alpha$ denotes a generic phase and $P$ a generic cell.

\section{Appendix C. Validation}

The closure relationships described before have been validated using the fluidized bed studied experimentally and computationally by Almuttaharet al.under various fluidization regimes [3]. Here, for the sake of brevity we show only the results for the fast fluidization case ("Case 6" in [3]).

The experimental riser, with a diameter of $76 \mathrm{~mm}$ and a height of $6.1 \mathrm{~m}$, is modeled as a transient, two-dimensional problem with $60 \times 2400$ cells. Fluid catalytic cracking (FCC) 
(a) Volume-fraction

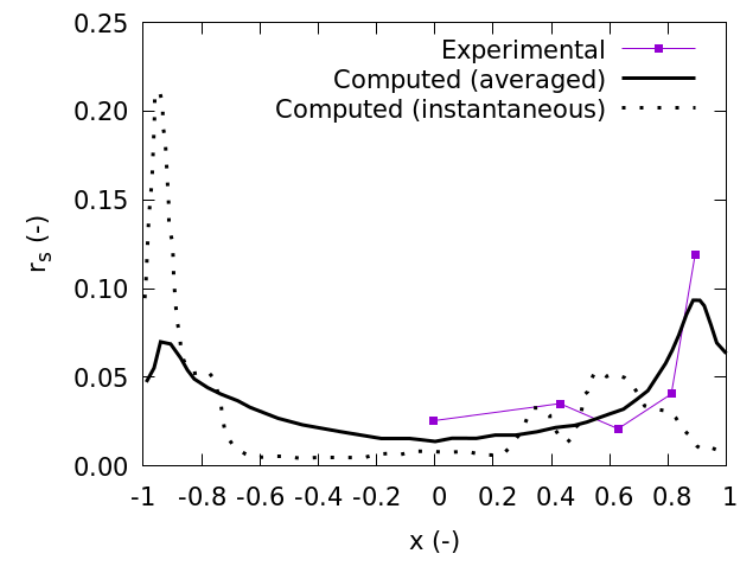

(b) Velocity

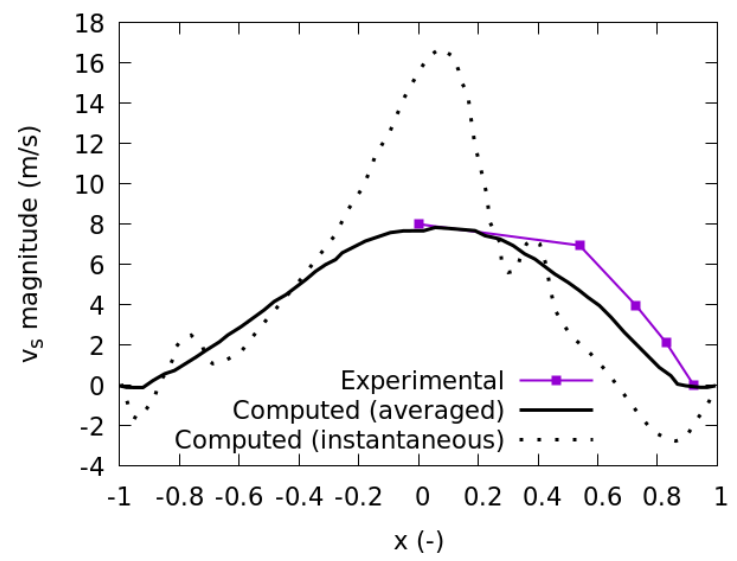

Figure C.17: Cross-stream profiles of solid-phase volume-fraction (a) and velocity (b) at $3.8 \mathrm{~m}$ from the bed bottom. Comparison of experimental and computational results. $x$ is the dimensionless cross-stream coordinate.

particles are represented using one solid phase with a diameter of $70 \mu \mathrm{m}$ (the mean experimental diameter) and density $1600 \mathrm{~kg} / \mathrm{m}^{3}$. Figure C.17 shows horizontal profiles of solid phase velocity and volume fraction at a height of $3.8 \mathrm{~m}$. The time-averaged computational profiles reproduce fairly well the experimental data. The figures includes also profiles of instantaneous values obtained in the transient simulation of the bed. The core-annulus pattern is clearly reproduced.

The consistency of the developed multiphase method has been previously reported by the authors in a previous paper [15]. There we show that solving a single-phase flow or a multiphase one with two identical phases lead to the same results. 